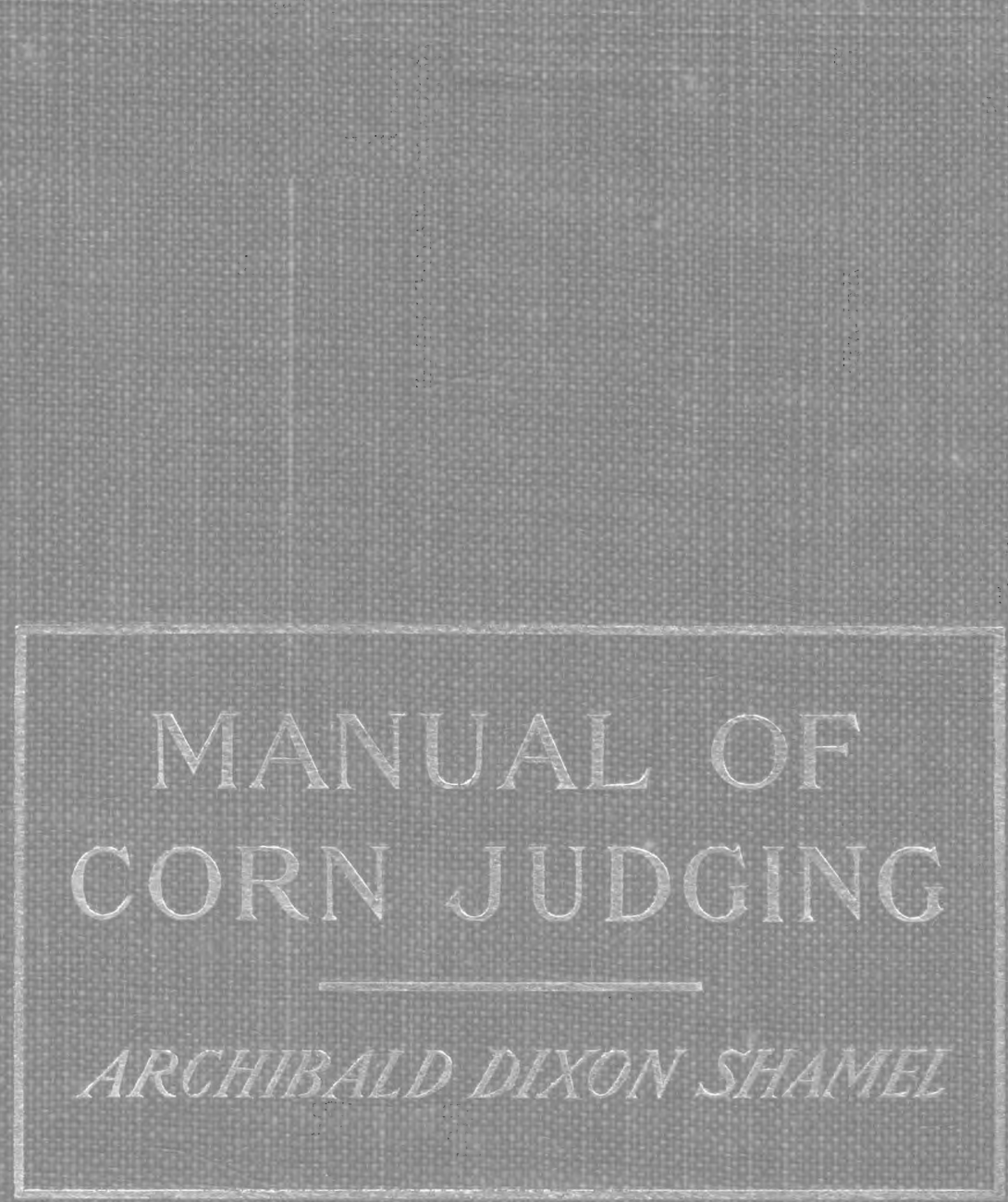




\section{Cornell ânípersitp}

\section{Tíbrary \\ OF THE}

Thew Work state College of Algriculture

C.u. 2547 . 


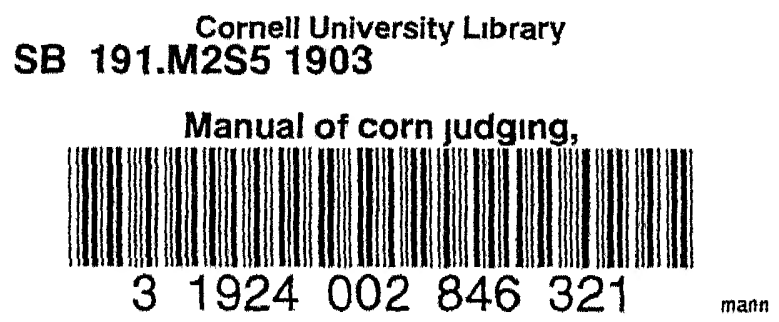





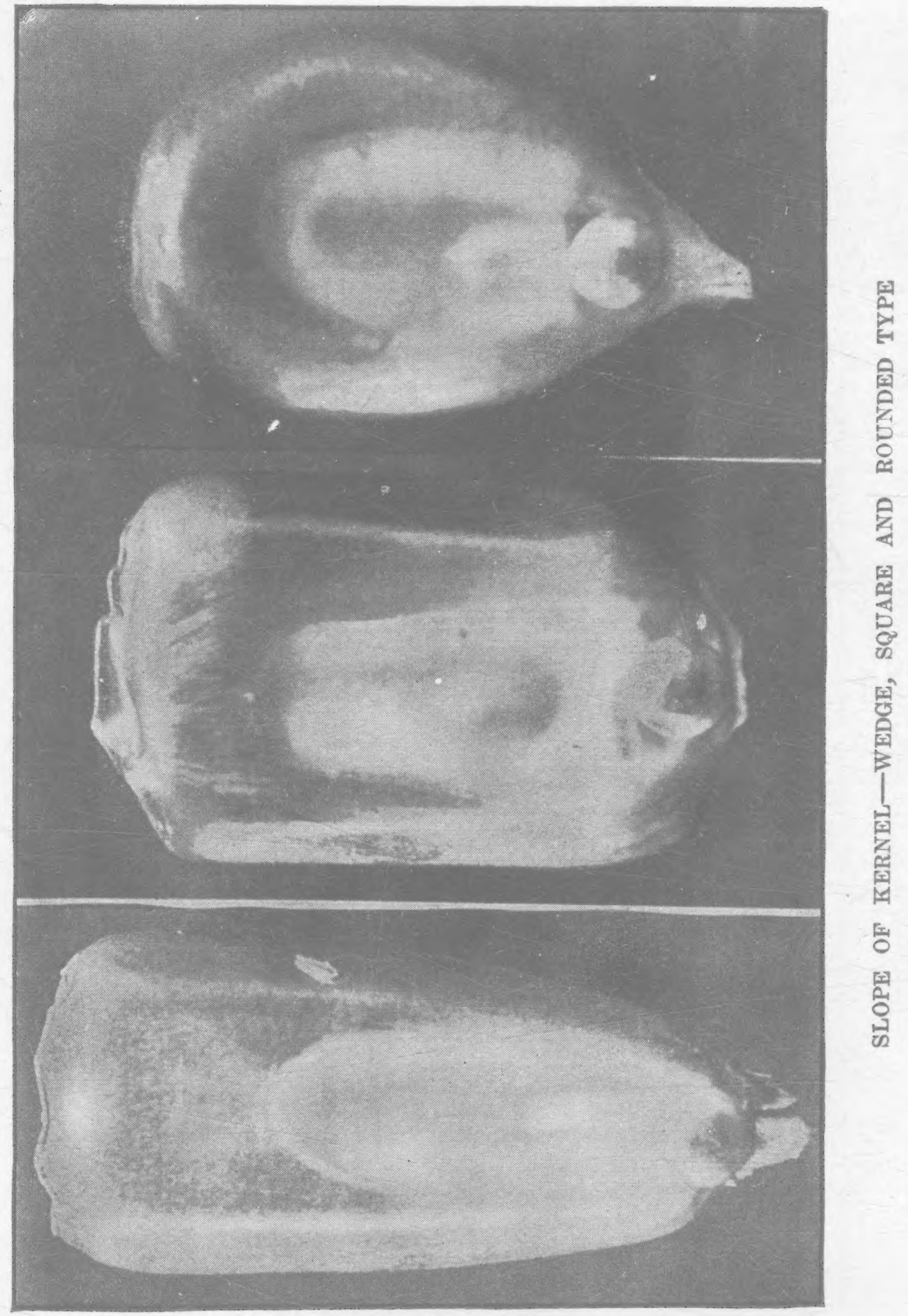




\section{Manual of}

Corn Judging

By

ARCHIBALD DIXON SHAMEL

Sermin Enitumt

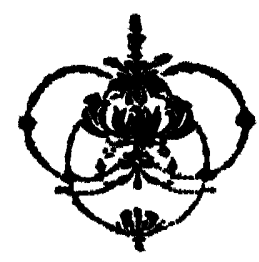

NEW YORK

ORANGI JUDD COMPANY

52 LAFAYETTE PLACE

IgO3 
Copyright 1903

by

Orange Judd Company 


\section{Dedication}

To the Illinois Corn Growers' and Seed Corn Breeders' Associations, representing, as they do, the first organized attempts to extend the production and improve the quality of the greatest of cereals, this little Manual is respectfully dedicated.

The Author. 



\section{Preface}

The preparation of the first edition of this Manual of Corn Judging was prompted by the need of such an outline in my class room. During the following winter it was found to be useful in the work of the various schools of corn judging, farmers' institutes, fairs and like places, where corn was studied. The entire edition was quickly exhausted, and in response to a continued call for additional copies I have made arrangements to issue this edition. In view of the constant improvements in the methods of judging samples, I have taken the opportunity to make a few changes and additions to the matter presented in the first issue.

I beg leave to express my sincere thanks for aid in the preparation of this work, to Mr. C. A. Shamel and others who have kindly assisted me in the arrangement of the material in the Manual.

It will probably be necessary to issue editions every year or so, in order to keep abreast of discoveries and the results of investigations in corn. In this way it will be possible to present the very best information to the corn students.

U. S. Dept. Agriculture,

A. D. SHAMEL.

Washington, D. C., Aug. 26, 1908. 



\section{Table of Contents}

Preface $\ldots \ldots \ldots \ldots \ldots \ldots \ldots \ldots \ldots \ldots \ldots \ldots \ldots \ldots$

How to Hande Samples . ................. 11

OutLine for Premium List . .................. 19

Rules Governing Exhibits ................ 23

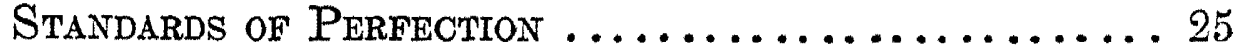

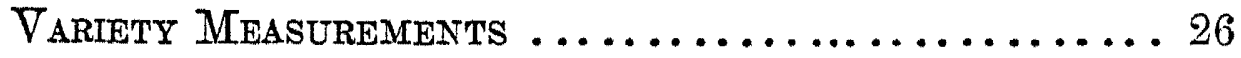

Iowa Score Card and Rules for Judgnig ........ 2 \%

Indiana Score Card and Rules for Judgiti ....... 31

Nebraska Score Card and Rules for Judging ....... 33

Kansas Score Card and Rules for Judging ........ 35

Illinors Score Card and Rules for JudgIng . . . . . 3 ל

Study of Characteristics . ................. 39

The Work of Scoring .................. 47

Testing the Vitality of Seed Corn ........... 55

Storing Seed Corn ....................... 6 \%

Arrangement of Score Record .............. 69

ARRANGEMent for Individuad SaMpie $\ldots \ldots \ldots \ldots \ldots 71$

Arrangement for Generat Sample $\ldots \ldots \ldots \ldots \ldots .72$ 



\section{Corn Judging}

The object of corn judging is to compare samples of corn by a uniform standard in order to determine the best sample for seed, and by best seed corn is meant that which will yield the most corn of the highest quality either for feeding or for market, and is consequently the most profitable to grow. The method consists in comparing the samples of corn with the standard scale of points which is supposed to contain all of the qualifications of the best seed corn, viz:

First, those points that insure high quality for consumption, such as soundness, maturity, etc.

Second, such as insure good yield, as size, uniformity, shape of ears, shape of kernels, well filled butts and tips, per cent of corn, etc.

Third, such as insure a perfect stand, as the per cent and vigor of germination.

Fourth, if the sample be a pure bred variety, such as trueness to color and type and the characteristics of that variety.

Fifth, the value of the sample for feeding or manufacturing purposes, such as the comparative per cent of oil, protein and starch in its composition.

These standards have been arranged and developed by experienced growers and corn experts, so that a sample which best fills their conditions has been found to be the best yielding, has the highest degree of vitality and is the most profitable corn to grow. The standards for the different races of dent corn have not been developed and perfected so that a standard for each race can be pre- 


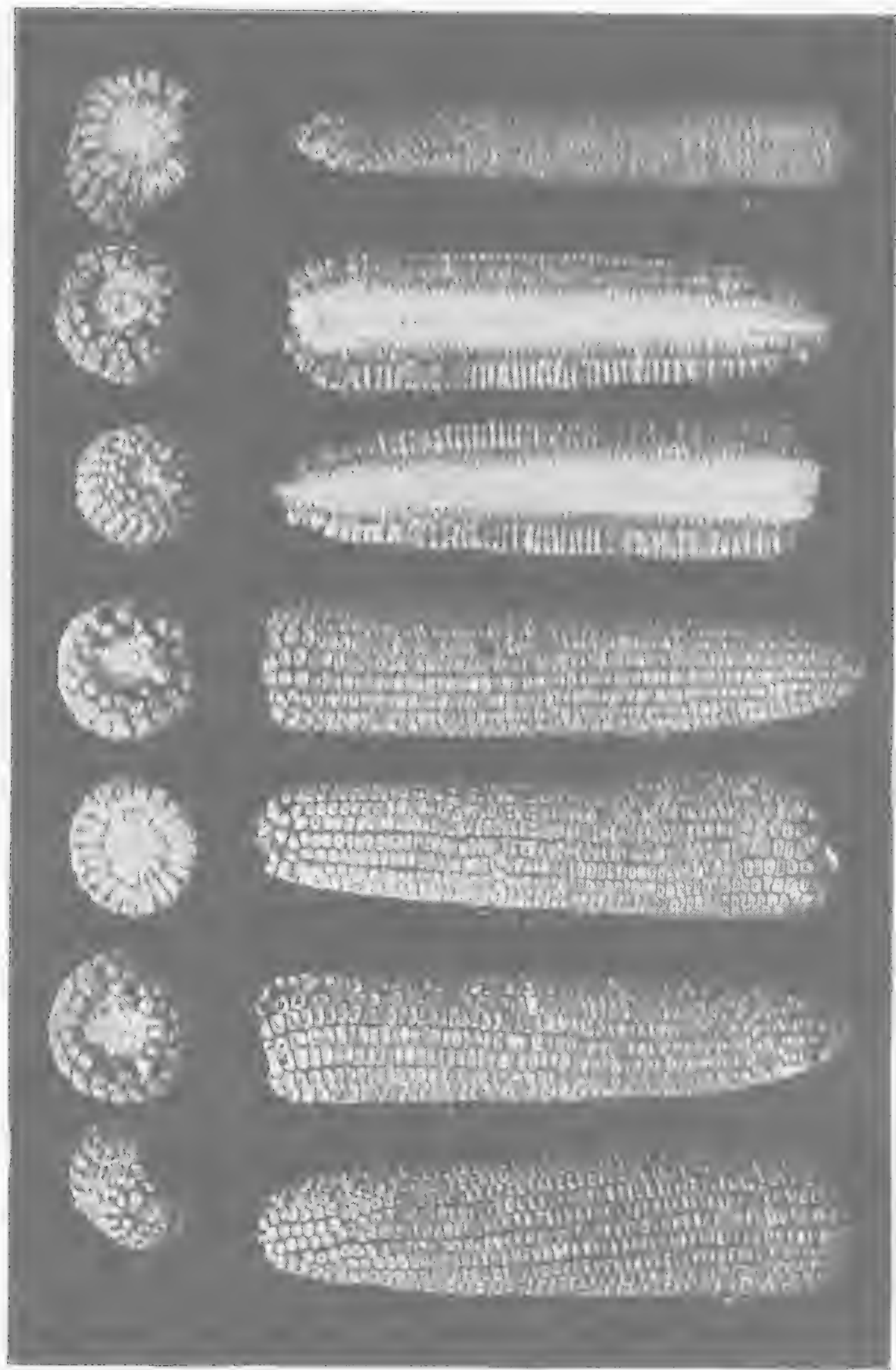

年 
sented in this manual. There is little doubt, however, that the next step in advance in corn judging will be the production of a separate standard for each race.

From the fact that corn is affected by and responds to climatic conditions, so that there is a difference in some of the characteristics of a race grown in one state compared with samples produced in another state, it has been found advisable to adopt score cards for each state, modified to take into account the differences which arise from growing the races under different climatic and soil conditions. These general score cards used in judging exhibits of corn in the different states are presented in the following pages, but the general considerations which must be taken into account in judging samples of corn in any state are the same. In other words, the principles of judging apply to all conditions and must be thoroughly understood in order to judge corn successfully.

On the judging table it is absolutely necessary to keep this fact in mind, viz: that the judge is not only to compare one sample with another, but each with the standard separately and independently, in order that its individual proper ranking may be determined. It is a good plan to keep the scores of all of the different samples in any one exhibit, laid out side by side, so that at any time a comparison of scores may be easily made. It is advisable in scoring any point in a sample to have the samples previously judged so arranged that by a glance the marking given to that point in the samples already judged can be seen and taken into consideration in determining the score of the sample in hand on that point.

The score cards and standards of perfection are useful as guides to the careful study of the characteristics of a sample of corn, consequently to the sample as a whole. However, if the score cards are used in an absolute mathematical sense, certain points which cannot 


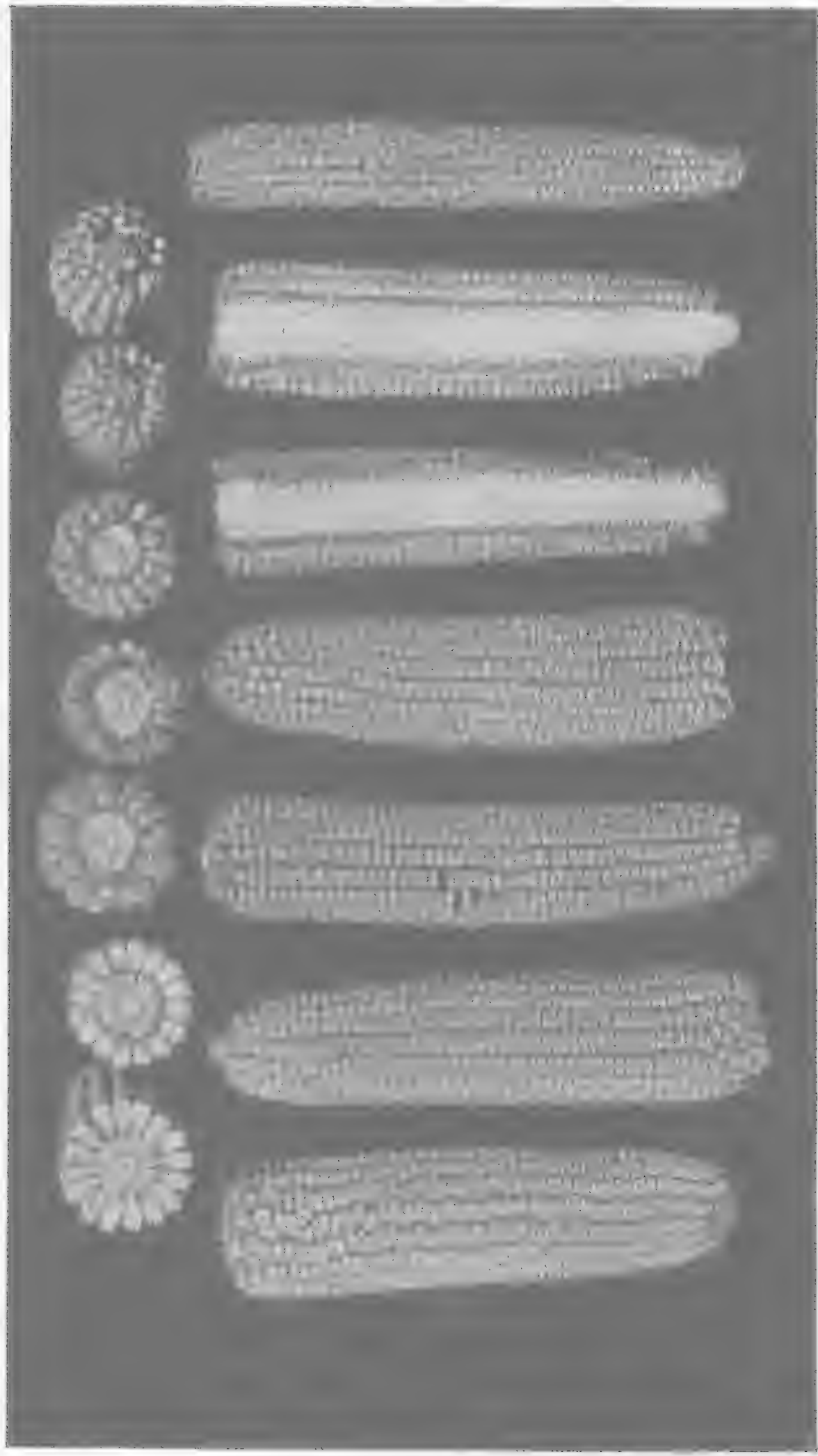

告 
be taken into account in the preparation of a score card interfere with the results and frequently cause a wrong decision, e. g., with the uniformity of exhibit. In other words, there are no absolute rules which can be laid down by which samples of corn can be properly judged. The judgment of the person who is comparing the samples must enter into the score, and his experience guide him in marking each point in the score card.

In exhibits of corn ten ears usually constitute a sample. This number makes it possible to get a fair idea of the general uniformity of the race, and at the same time it offers a convenient number for the necessary calculations in the scoring of the samples. However, the number of ears is a matter which must be decided by the judges, and will necessarily vary under certain conditions. Other things being equal, a large number of ears is better than a small number. Of course exceptions must be made for exhibits of best individual ears and other cases, in which event the sample is scored in the same manner as an exhibit of ten ears, and the total score multiplied by ten in order to have all the scores on a uniform basis. Where one hundred ears, more or less, are presented as a sample, it will be found to be most convenient to take out ten ears, say every tenth ear, and judge this sample for all of the points except uniformity and other general characteristics where the entire sample may be taken into consideration.

In selecting corn for an exhibit great care should be taken that the individual ears are not injured in any way. By carelessly dropping an ear part of the kernels may be shelled off or mutilated. This will interfere in determining the per cent of corn in the ear, and leave doubt as to the purity of the color of the grains. The judge may take into account the actual condition of the sample, so that every missing grain or injury will reduce the total score. During the process of judging 


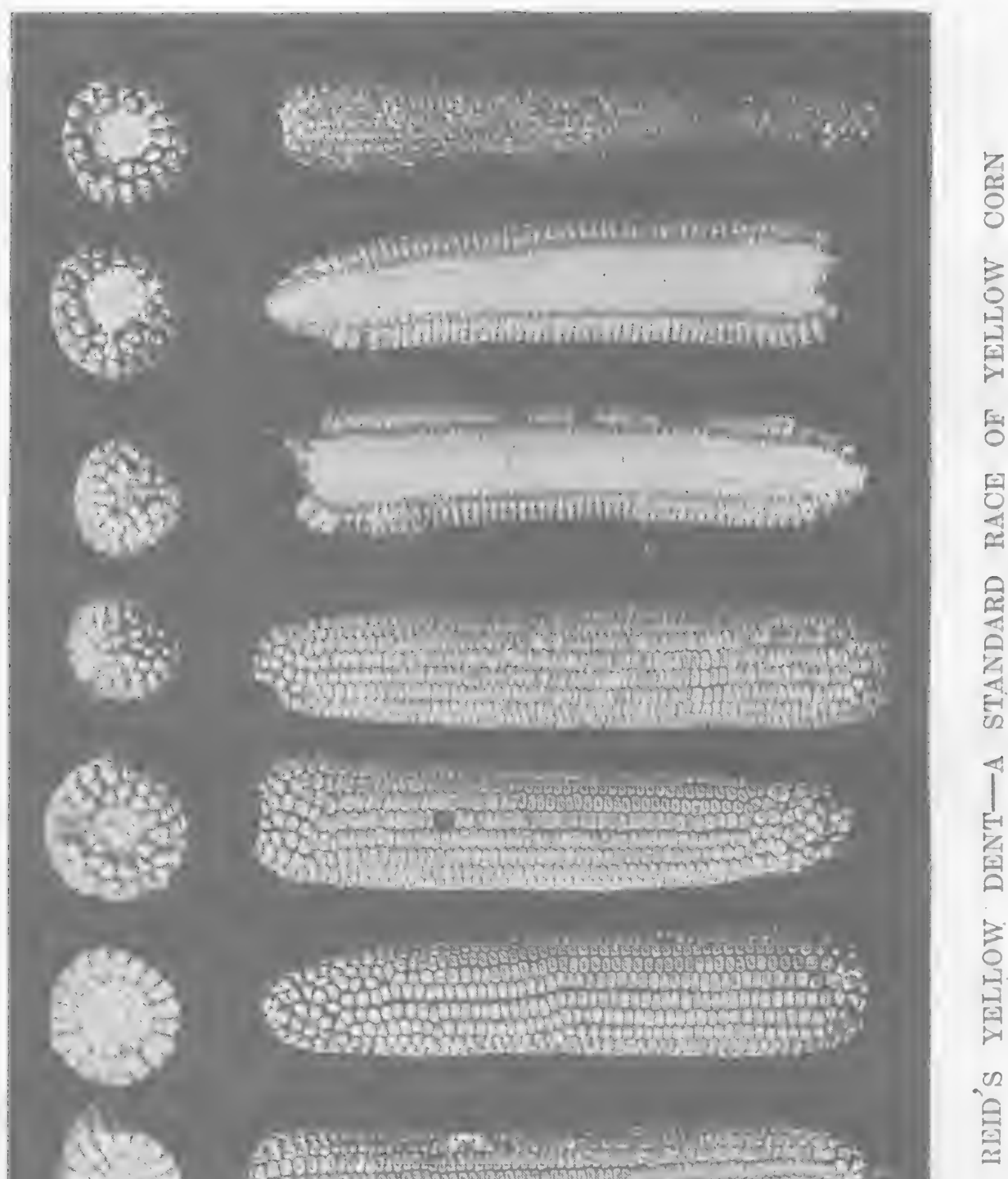

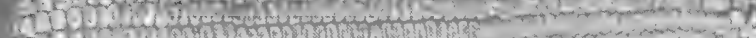

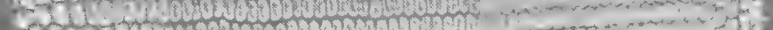

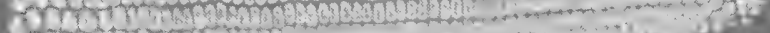

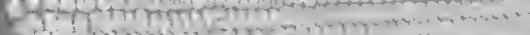

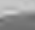


the ears should be handled as little as possible consistent with a careful examination of all points. The ears should always be laid down in the same order as taken up, and in such manner that the ears will not be injured in any way. In no case is it necessary to twist or break the ears, in this way injuring them for future examination. All of these points are matters of training and experience, and all judges should be required to show evidence of a course of training in this work which fits them for their duties.

In judging corn it is necessary to expedite matters as much as possible. All unnecessary moves must be left out. The eye must be trained to accurately judge any one point at first examination. Ten minutes is long enough to judge all points in a sample, except shelling representative ears to determine the per cent of corn on the ear. In order to make a close and accurate comparative study, it is advisable to lay all of the samples in any one class side by side on some convenient table. This table should be of convenient hight for working easily and without strain. The light should fall evenly over the entire exhibit, and it is absolutely necessary to have a strong light. Much of the difference in color of kernels can only be detected by the closest observation in the best possible light. In all cases a good light must fall on the tips of the ears, and the judging table should be arranged so that one can easily and quickly examine the tips and butts of ears by bending over the table.

\section{Classification}

The samples of corn in exhibits are usually entered under some general system of classification. This method has been necessary from the fact that distinct races have not been recognized by growers or breeders. In other words, there has been no uniform basis for a classi- 


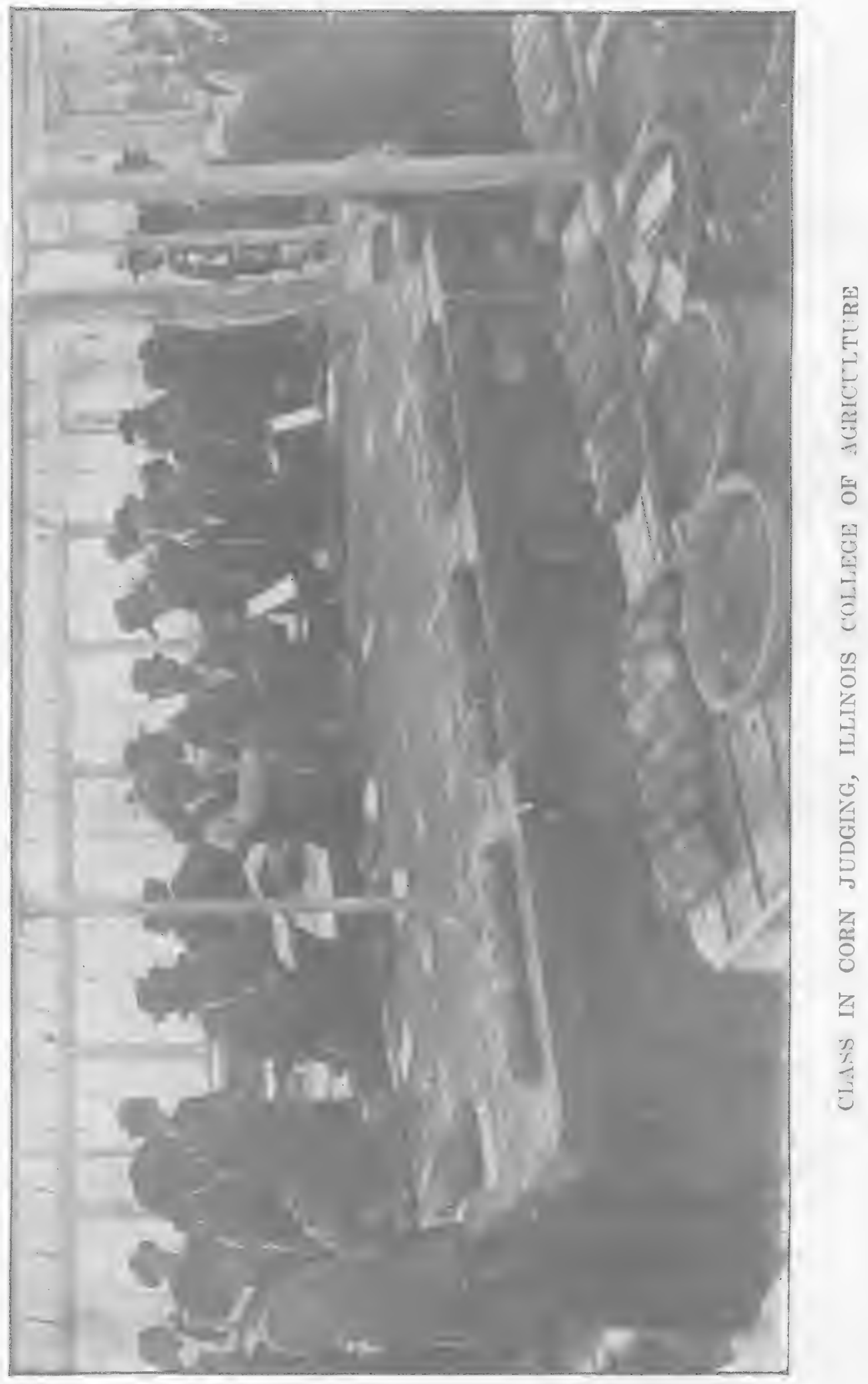


fication of the samples. With the advent of the state corn breeders' and growers' associations the matter of pure bred races of corn has been emphasized, and it has become possible to distinguish between the different races represented in the general exhibits of corn. For instance, the Illinois Seed Corn Breeders' association recognizes seven distinct races, viz: (White) Boone County White, Silvermine, White Superior, and (Yellow) Leaming, Reid's Yellow Dent, Riley's Favorite and Golden Eagle.

Other races are being developed in this state by the corn breeders, and other states naturally possess different races than those grown in Illinois. In order to stimulate this practice of growing standard races, it is advisable to arrange the premium list with that end in view. It should be the duty of every officer having in charge exhibits of corn to become familiar with the work of the corn breeders' and corn growers' associations of his state and arrange his premium list on the basis recommended by these organizations. Necessarily the premium lists will vary with different sections of any state, and particularly as between different states, but the principle underlying their arrangement holds true under all conditions. In every case the object of corn exhibits is to benefit the interests of corn, therefore the premium lists should be carefully arranged so that the final result of this work will be a permanent benefit to the corn growing interests.

\section{Outhine for Premium IIst}

The greatest cause of confusion in the development of pure bred races of corn arises from differences in ideas as to the characteristics of any race among breeders and growers. A comparison of typical samples of the different races of corn in exhibits is probably one of the most effective means of disseminating information in regard to the characteristics of any race. This is 


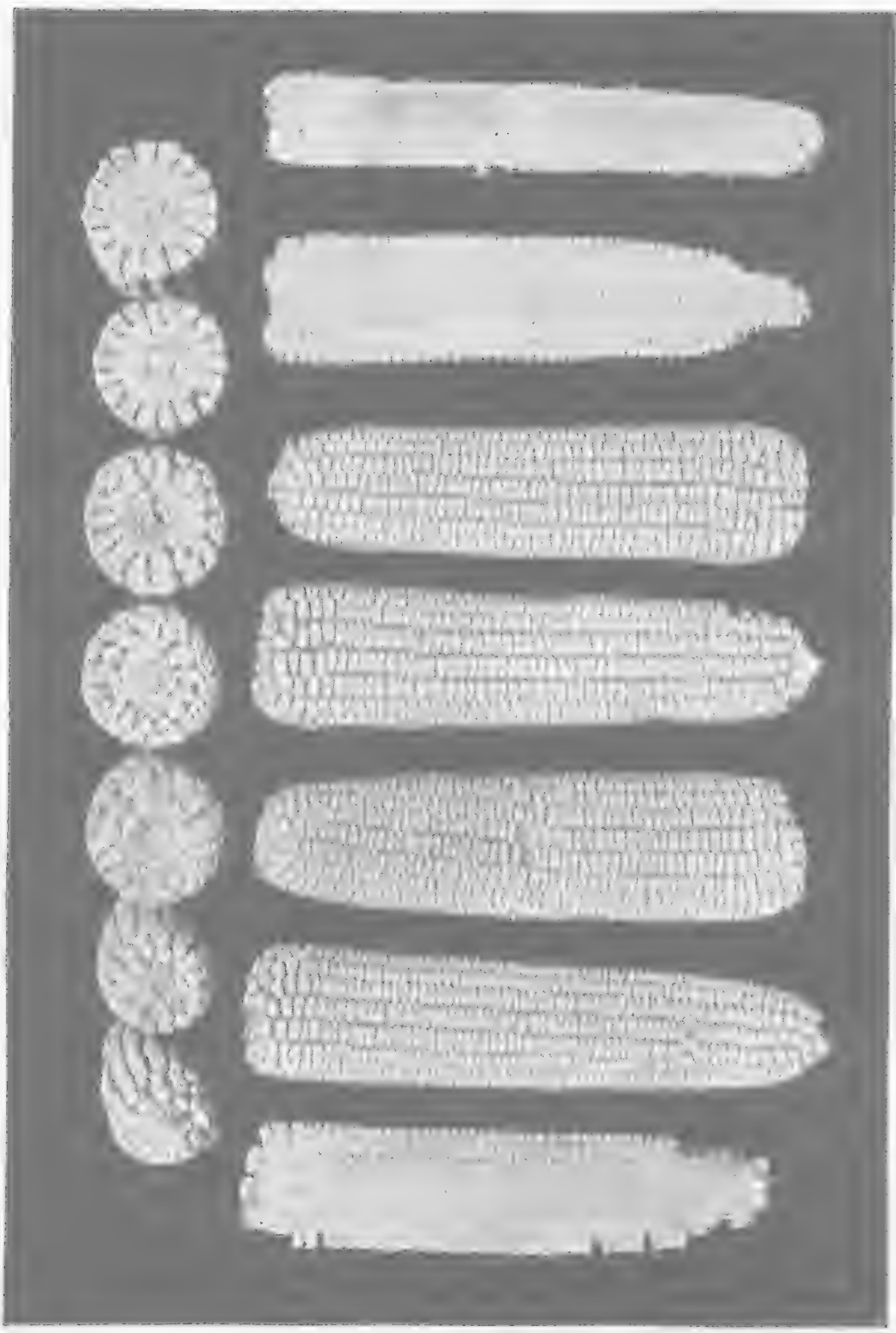

 
particularly true if the exhibit is so arranged that a comparison of samples belonging to different races can be easily made. It follows, therefore, that the outline of the premium list should be such as to assist in bringing the samples together in such manner that will permit of study by growers and visitors who inspect the exhibit. In order to assist the officers of shows, fairs and other places where corn is exhibited, the following brief outline for a premium list is given:

\section{CleAss A}

Prizes for best samples of 10 ears of standard varieties of white corn. 1st premium, $\$ 5.00 ; 2 \mathrm{nd}, \$ 3.00 ; 3 \mathrm{rd}, \$ 1.00$.

Lot 1. Boone County White.

Lot 2. Silvermine.

Lot 3. White Superior.

Lot 4. Other Varieties.

\section{Class B}

Prizes for best samples of 10 ears of standard varieties of yellow corn. 1st premium, $\$ 5.00 ; 2$ nd, $\$ 3.00 ; 3 \mathrm{rd}, \$ 1.00$.

Lot 1. Leaming.

Lot 2. Reid's Yellow Dent.

Lot 3. Golden Eagle.

Lot 4. Riley's Favorite.

Lot 5. Other Varieties.

\section{Class O}

Prizes for best samples of 10 ears of mixed varieties. 1st premium, $\$ 5.00 ; 2$ nd, $\$ 3.00 ; 3 \mathrm{rd}, \$ 1.00$.

Lot 1. Early.

Lot 2. Medium.

Lot 3. Late. 


\section{Class D}

Prizes for best bushels of corn. 1st premium, $\$ 25.00$; 2nd, $\$ 15.00 ; 3 \mathrm{rd}, \$ 10.00$.

Lot 1. White.

Lot 2. Yellow.

Lot 3. Mixed.

\section{Crass E}

Prizes for best ears of corn. 1st premium, $\$ 1.00$; 2nd, \$.50; 3rd, \$.25.

Lot 1. Boone County White.

Lot 2. Silvermine.

Lot 3. White Superior.

Lot 4. Leaming.

Lot 5. Reid's Yellow Dent.

Lot 6. Riley's Favorite.

Lot 7. Golden Eagle.

Lot 8. Other Varieties.

Class $\mathbf{F}$

Prizes for best samples of 10 ears of varieties of sweet corn.

\section{Class G}

Prizes for best samples of 10 ears of varieties of pop corn.

\section{Crass H}

Prizes for best samp?es of 10 ears of any varieties of dent corn. 


\section{Class I. Special Premiums}

Under this head, and further classes, special premiums for particular purposes may be offered.

\section{Rules Governing Exhibits}

1. Only one entry can be made by an exhibitor in any class.

2. An exhibitor is barred from exhibiting in more than three classes.

3. The samples of corn must have been grown by the exhibitor during the summer immediately preceding the exhibition.

4. The samples must not be treated unfairly by taking out poor and mixed or otherwise injured kernels and replacing them by good ones, but grooming of the ears in such manner as to allow of the best possible natural presentation is strongly recommended. Any unfair or "tricky" occurrences bar the exhibitor from all entries and all privileges of the exhibition.

5. Corn for exhibition must be delivered to the ex" hibit committee three days before the opening of the exhibition, carefully labeled with the name of the exhibitor, date, address, lot and class under which the sample is to be exhibited. This label should be pasted conspicuously on the outside of the package in which the sample is sent and tied on at least one of the ears of the sample.

6. The exhibits are all subject to all necessary handling by the judges, but remain the property of the exhibitor and may be secured by him immediately after the exhibit is closed and awards made.

7. No professional corn breeder, seed dealer or expert judge will be allowed to exhibit, except in classes specially arranged for them. 


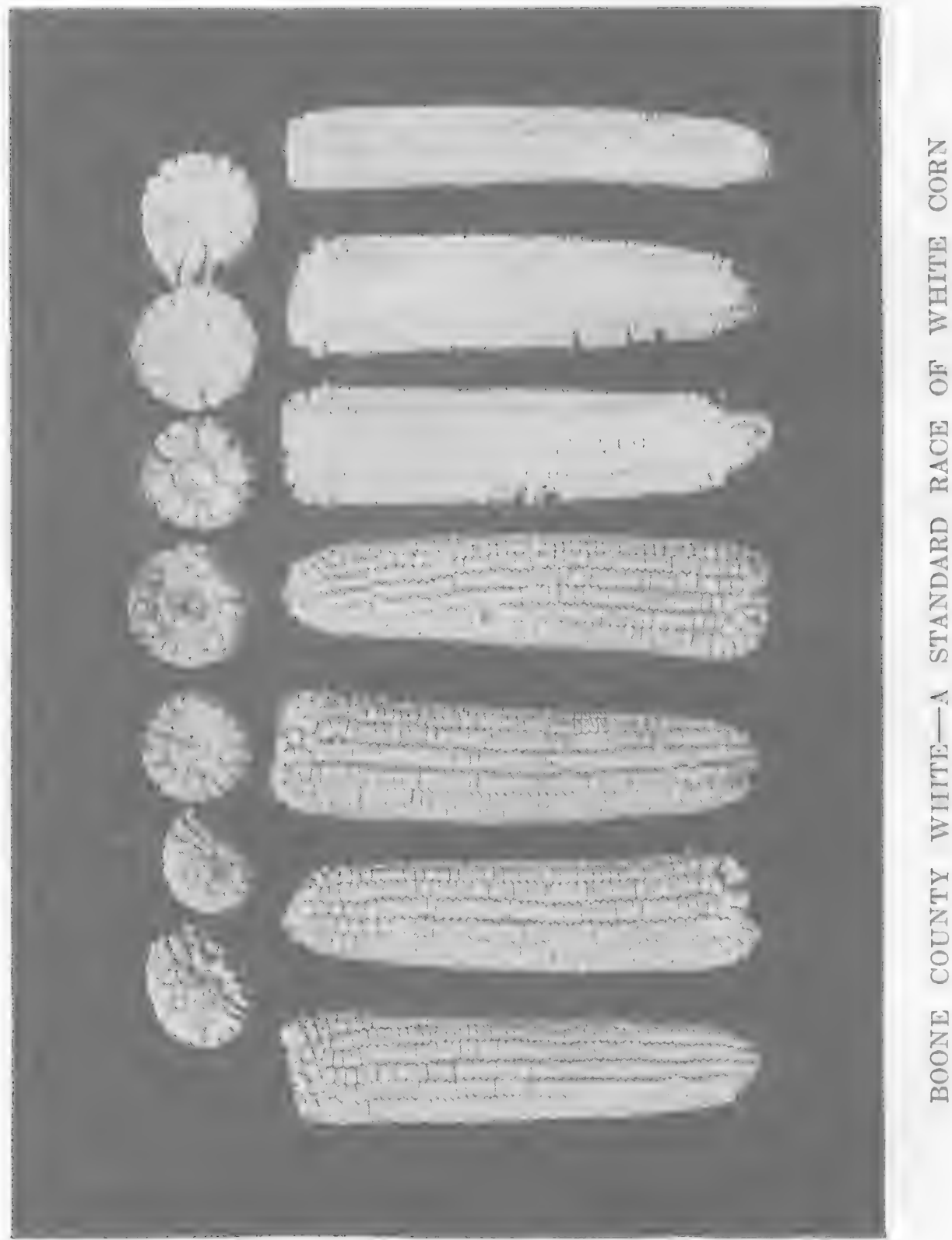


8. Exhibits must be sent with all charges prepaid.

9. Competition open to state in all classes.

10. Lot 1 , class $A$, and lot 1 , class $B$, and class I open to competition of the world.

11. All exhibits are to be judged by expert judges holding certificates as such, and according to the score cards and standards of perfection adopted by the State Corn Growers association.

The above outline for premium lists and rules governing exhibits are simply suggestions embodying the principles underlying successful exhibitions of corn. It will be found necessary in every case to adapt the premium lists and rules to local conditions and circumstances.

\section{Standards of Perfection}

By standards of perfection is meant the types which breeders and growers recognize as the best and most desirable, and to which evcry effort is directed in bringing up the individuals of the races. Standards must be developed in the case of new races, and old standards changed during the process of the improvement of the established races. In order to aid in the development of these standards, the following table of standards of perfection for the established races is presented: 
MANUAL OF

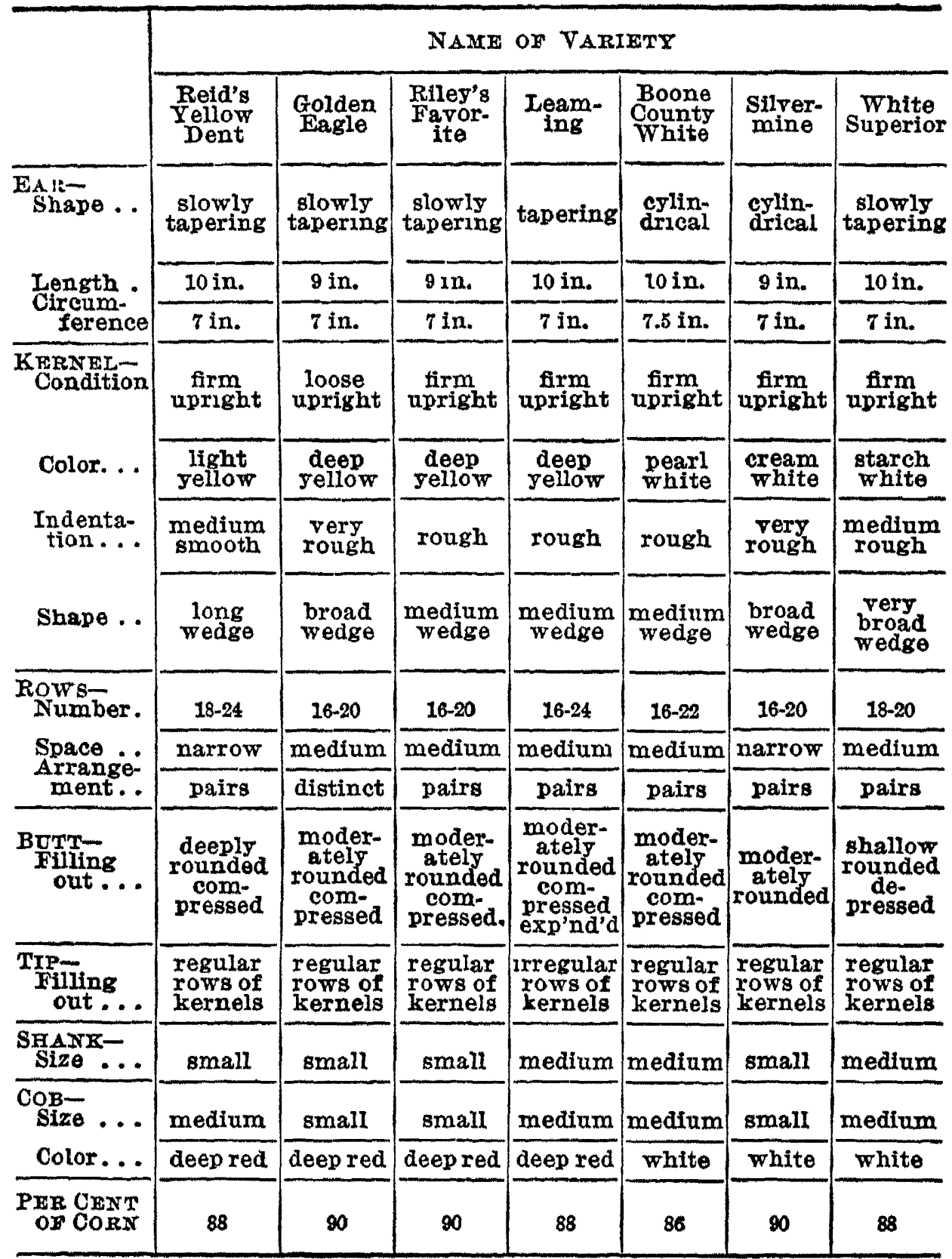

SCORE CARDS

In view of the fact that the different states have adopted and use different score cards, owing to well recognized differences in soil, climate and other conditions of production, it will be necessary to present the score cards adopted by each state separately. 


\section{Iowa Score Card ANd Rules for Judging}

\begin{tabular}{|c|c|c|c|}
\hline & & & EXPLANATION \\
\hline & $\begin{array}{l}\text { POINTS } \\
\text { Trueness to type or }\end{array}$ & 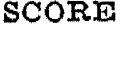 & The ten ears of the sample \\
\hline & $\begin{array}{l}\text { breed characteris- } \\
\text { tics } \ldots . . . \ldots \ldots \ldots \ldots \ldots\end{array}$ & 10 & $\begin{array}{l}\text { should possess similar or like } \\
\text { characteristics and should be } \\
\text { true to the variety which they }\end{array}$ \\
\hline 2 & Shape of ears.......... & 10 & $\begin{array}{l}\text { represent. } \\
\text { The shape of the ear should } \\
\text { conform to variety type, taper- } \\
\text { ing slightly from but to tip, } \\
\text { but approaching the cylindrical. }\end{array}$ \\
\hline 3 & $\begin{array}{l}\text { Color- } \\
\quad a \text { Grain } \ldots \ldots \ldots \ldots \\
\quad b \text { Cob } \ldots \ldots \ldots \ldots\end{array}$ & $\begin{array}{l}\mathbf{5} \\
\mathbf{5}\end{array}$ & $\begin{array}{l}\text { Color of grain should be true } \\
\text { to variety and free from mix- } \\
\text { ture. White corn should have } \\
\text { white cobs, yellow corn red cobs. }\end{array}$ \\
\hline$t$ & Market condition.... & 10 & $\begin{array}{l}\text { The ears should be sound, firm, } \\
\text { well matured and free from } \\
\text { mold, rot or insect injuries. }\end{array}$ \\
\hline 5 & Tips & 5 & $\begin{array}{l}\text { The tips of the ears should not } \\
\text { be too tapering and should be } \\
\text { well filled with regular, uniform } \\
\text { kernels. }\end{array}$ \\
\hline b & Butts . & $\mathbf{5}$ & $\begin{array}{l}\text { The rows of kernels should } \\
\text { extend in regular order over the } \\
\text { butt, leaving a deep impression } \\
\text { when the shank is removed. } \\
\text { Open and swelled butts are ob- } \\
\text { jectionable. }\end{array}$ \\
\hline$\gamma$ & $\begin{array}{l}\text { Kernels- } \\
\quad \text { o Uniformity ...... } \\
\quad b \text { Shape ........... }\end{array}$ & $\begin{array}{r}10 \\
5\end{array}$ & $\begin{array}{l}\text { The kernels should be uniform } \\
\text { in shape, size and color, and } \\
\text { true to the variety type. The } \\
\text { kernels should be so shaped that } \\
\text { their edges touch from tip to } \\
\text { crown. The tip portion of the } \\
\text { kernel is the richest in protein } \\
\text { and oil, and hence of the high- } \\
\text { est feeding value. For this rea- } \\
\text { son the tip portion should be } \\
\text { full and plump. }\end{array}$ \\
\hline 8 & Length of ears....... & 10 & $\begin{array}{l}\text { Northern section } 81 / 2 \text { to } 91 / 2 \\
\text { inches, central section } 83 / 4 \text { to } 93 / 4 \\
\text { inches, southern section } 9 \text { to } 10 \\
\text { inches. Long ears are objection- } \\
\text { able because they usually have } \\
\text { poor butts and tips, broad, shal- } \\
\text { low kernels, and hence a low } \\
\text { percentage of }\end{array}$ \\
\hline & $\begin{array}{l}\text { Circumference } \quad \text { of } \\
\text { ears } \ldots \ldots \ldots \ldots \ldots \ldots\end{array}$ & 5 & $\begin{array}{l}\text { percentage of corn to cob. } \\
\text { Northern section } 61 / 2 \text { to } 7 \\
\text { inches, central section } 6 \% \text { to } 71 / 4 \\
\text { inches, southern section } 7 \text { to } 71 / 2 \\
\text { inches. }\end{array}$ \\
\hline & $\begin{array}{l}\text { Space- } \\
\text { a Furrows be- } \\
\text { tween rows...... } \\
b \text { space between } \\
\text { kernels at cob.. }\end{array}$ & 5 & $\begin{array}{l}\text { The furrow between the rows } \\
\text { of kernels should be small. } \\
\text { Space between kernels near the } \\
\text { cob is very objectionable. }\end{array}$ \\
\hline & $\begin{array}{c}\text { Proportion of grain } \\
\text { to cob..................... }\end{array}$ & 10 & ned by weik \\
\hline
\end{tabular}




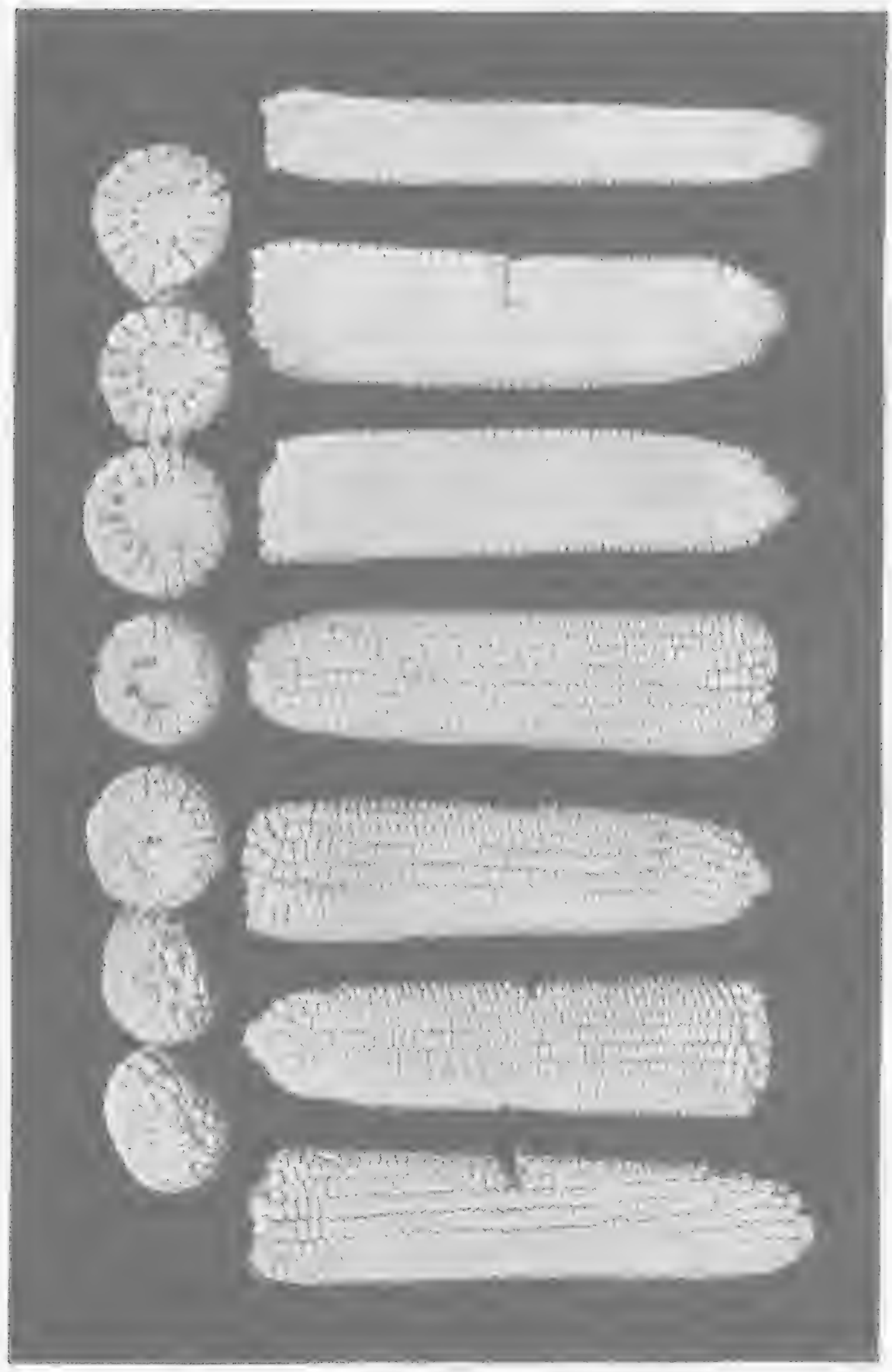




\section{RULES}

1. Length of Ear-The deficiency and excess in length of all ears not conforming to the standard shall be added together, and for every inch thus obtamed a cut of one point shall be made.

2. Curcumference of Ear-The deficiency and excess in circumference of all ears not conforming to the standard shall be added together, and for every two inches thus obtained a cut of one point shall be made. Measure the circumference at one-third the distance from the butt to the tip of the ear.

3. Proportion of Corn to Cob-Per cent of corn should be from 86 to 87 . In determining the proportion of corn to cob, weigh and shell every alternate ear in the exhibit. Weigh the cobs and subtract from weight of ears, giving weight of corn. Divide the weight of corn by total weight of ears, which will give the per cent of corn. For each per cent short of standard one and one-half points shall be made.

4. In judging corn, a red cob in white corn, or a white cob in yellow corn shall be cut at least two points. For one or two mixed kernels a cut of one-fourth point, for four or more mixed kernels a cut of one-half point shall be made. Kernels missing from the ear shall be counted as mixed. Difference in shade or color, as light or dark red, white or cream color, must be scored according to variety characteristics.

5. Scoring Tips-Where the full diameter of the cob is exposed a cut of one point shall be made and a proportionate cut as the cob is less exposed. Regularity of the rows near the tip and the shape and size of the kernels must also be considered in scoring tips.

6. Scoring Butts-If the kernels are uniform in size and extend over the butt in regular order give full marking. Small and compressed or enlarged or open butts are 


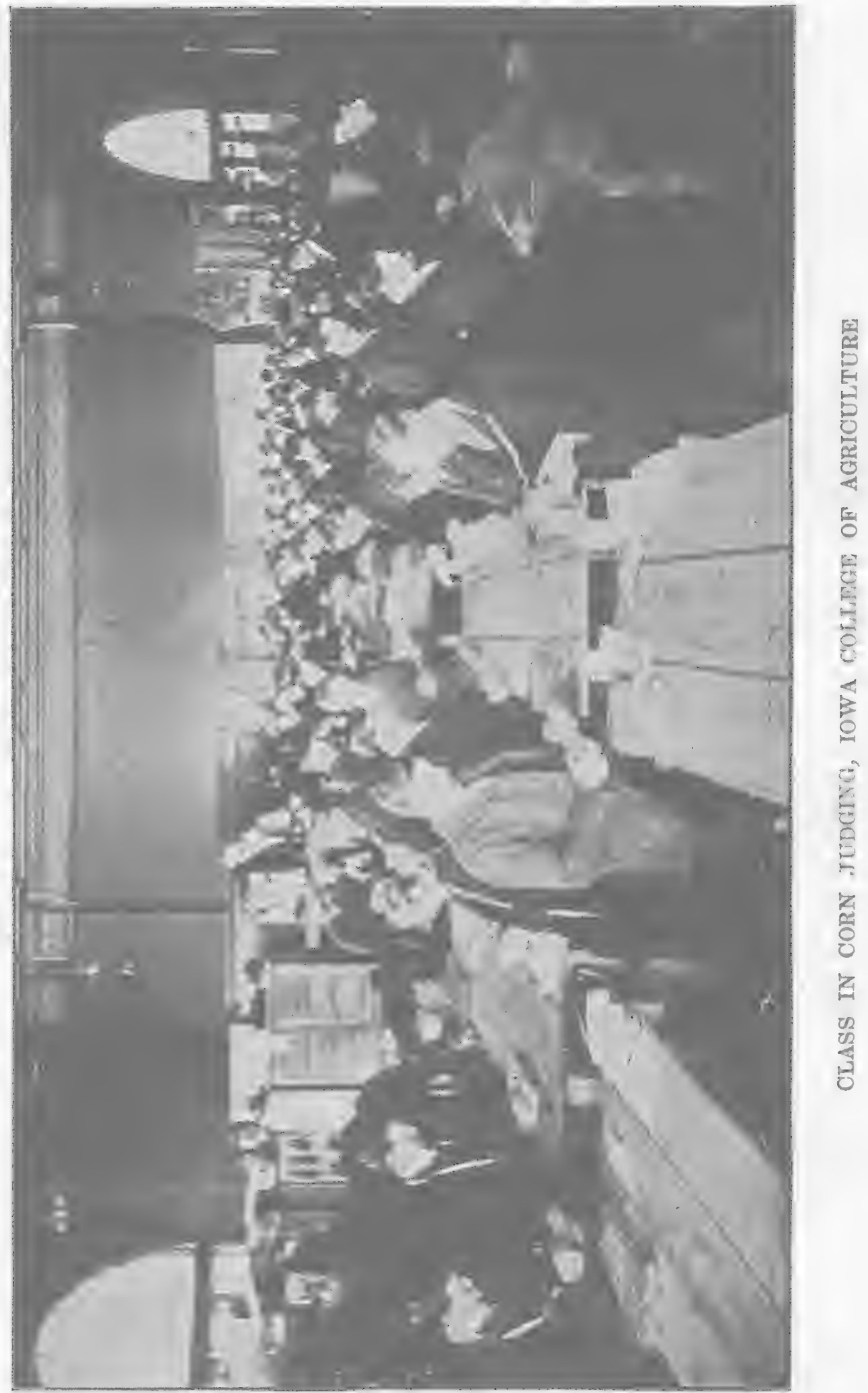


objectionable, as are also those with flat, smooth, short kernels, and must be cut according to the judgment of the scorer.

7. Each exhibit should consist of ten ears of corn.

Indiana Score Card

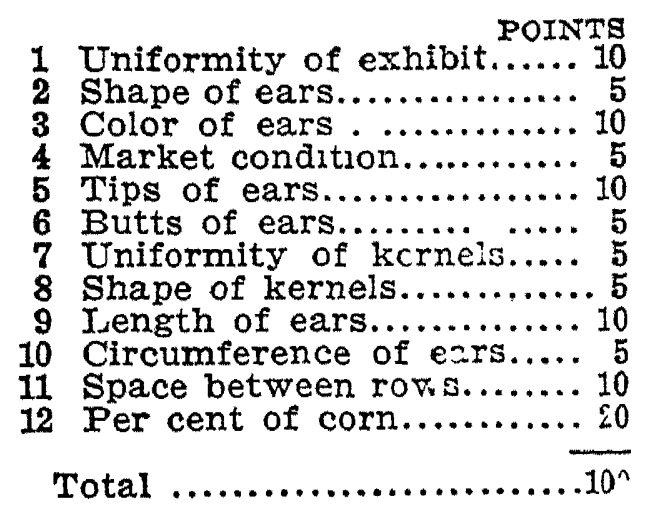

A perfect ear of corn should be from 10 to 12 inches long and $7 \frac{1}{2}$ to 8 inches in circumference. The ear should yield 88 per cent of grain.

The ear should taper but slightly, approaching the cylindrical to near the point. It should be well filled out at both ends, with straight rows of wedge-shaped grains.

Disqualifications: Red cobs in white corn; white cobs in yellow corn.

REASONS 


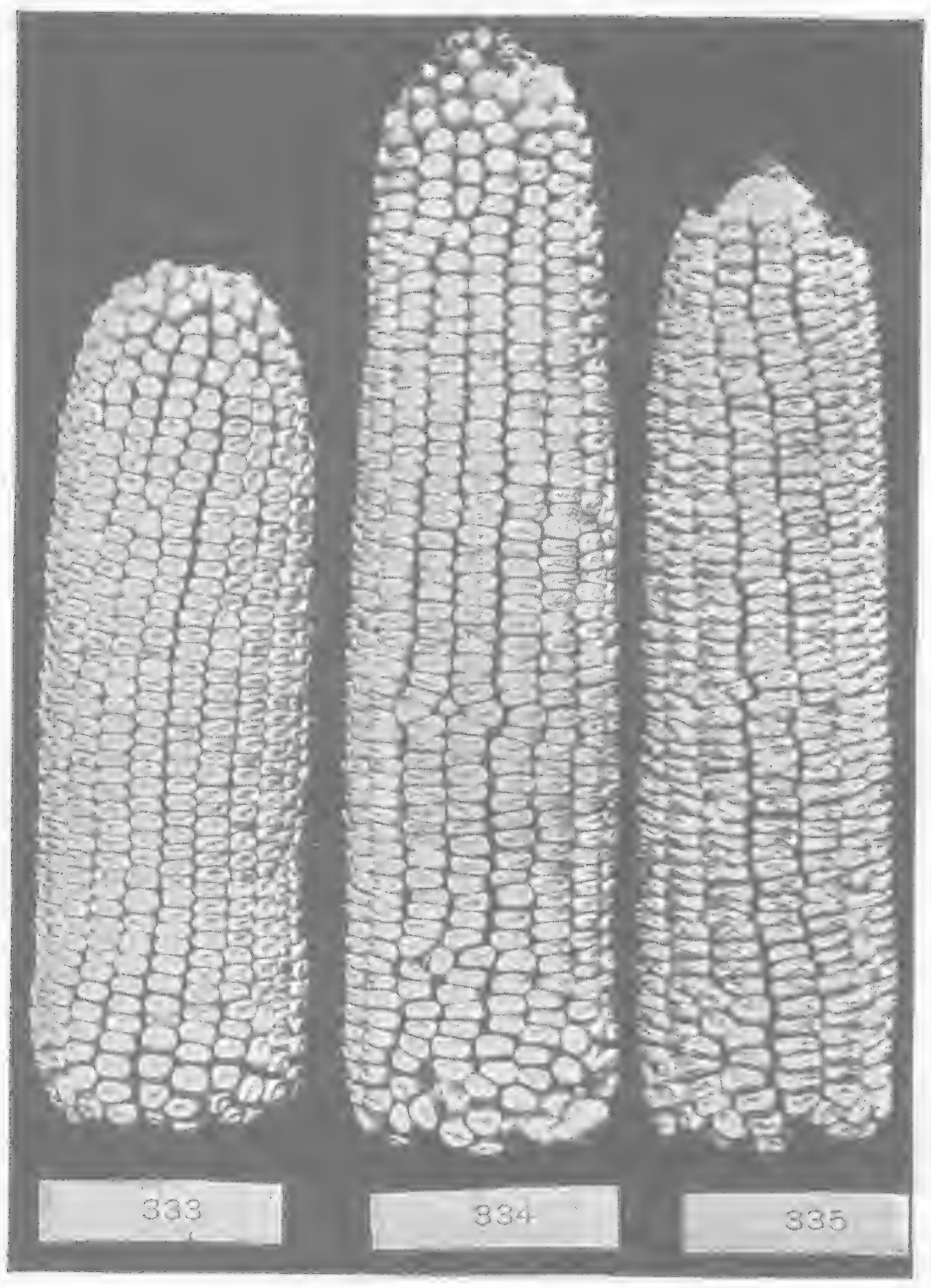

NOT UNTFORM-333 TOO SHORT, 334 TOO LONG, 335 VERY ROUGH 


\section{Nebraska Score Card}

\begin{abstract}
PERFECT
POINTS SCORE
\end{abstract}

1 Uniformity ........ 5

2 Trueness to type.....

3 Shape

4 Color...........$\ldots$.

5 Market condition....

6 Tips

7 Butts

8 Kernel uniformity...

9 Kernel shape

10 Length of ear........

11 Circumference of ear.
Each exhibit should consist of 10 ears. All of the ears in an exhibit should be uniform in size, shape, color and indentation. Cut each off ear .5 point.

All the ears in the exhibit should be true to the type and variety which they represent. Cut each off ear 1 point.

The shape of the ear should conform to the variety of the type. Cut each off ear .5 point.

The color of grain should be true to variety and free from mixture. White corn should have white cobs and yellow corn red cobs. For one mixed kernel on an ear cut .25 point; for two or three, cut .5 point; for four or five, cut .75 point; for more than five, cut 1 point.

The ears should be well matured, firm and sound. Cut .5 point for each immature or unsound ear.

The tips of the ears should not be too tapering and should be well filled with regular, uniform kernels. Cut 1 point for each tip exposed one inch; for less exposures and irregularities, cut in proportion.

The rows of kernels should be even and swell out evenly beyond the end of the cob. Cut 5 point for each poorly filled butt. For other irregularities, cut from 1 to 3 points.

The kernels should possess like characteristics and be true to variety type. Cut 5 point for each off ear.

The kernels should be so shaped that their edges touch from tip to crown. Cut .5 point for each poorly shaped pair.

The length should conform to the standard for the variety. Add together the deficiencies and excesses in length, and for each inch so obtained cut the exhibit 1 point.

Measure from one-third the distance from butt to tip and for each two inches of the sum of the deficiencies and excesses cut the exhibit 1 point. 


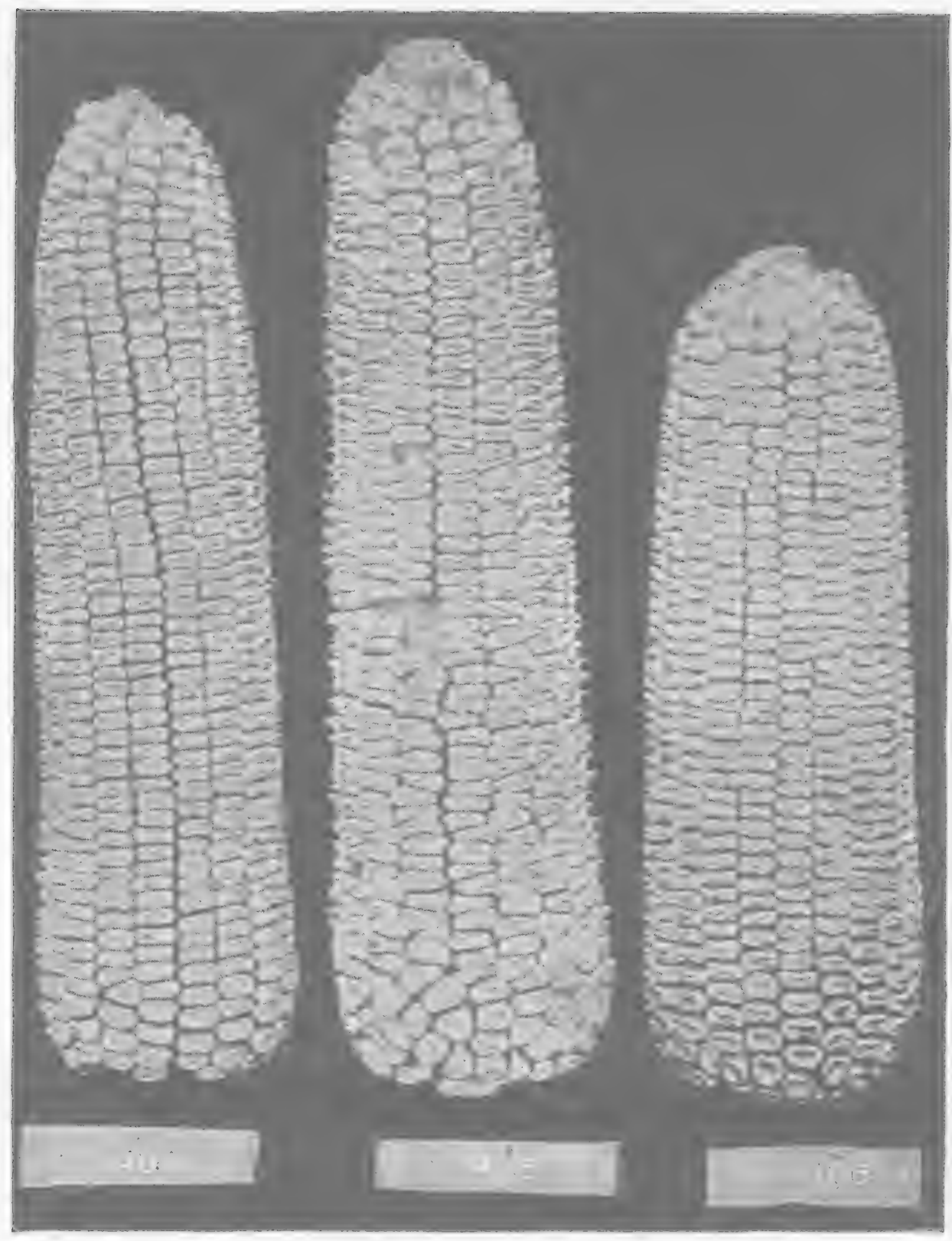

SLOPE OF FARS-CHARACTERISTICALLY UNDESIRABLE SLOPES 


\section{Nebraska Score Card-Continued}

\begin{tabular}{|c|c|c|c|}
\hline & POINTS & $\begin{array}{c}\text { PERFECT } \\
\text { SCORE }\end{array}$ & EXPLANATION \\
\hline 12 & Space...$\ldots \ldots \ldots \ldots$ & 5 & $\begin{array}{l}\text { The rows of kernels should be } \\
\text { close together from tip to crown. } \\
\text { Cut .5 point for each ear hav- } \\
\text { ing spaces between rows over } \\
1-16 \text { th of an inch; for spaces } \\
\text { over } 1-32 \text { inch, cut } 25 \text { point. }\end{array}$ \\
\hline 13 & $\begin{array}{l}\text { Proportion of corn to } \\
\text { cob } \ldots \ldots \ldots \ldots \ldots \ldots\end{array}$ & 20 & $\begin{array}{l}\text { Determined by shelling and } \\
\text { weighing half of the ears in the } \\
\text { exhibit. For every per cent be- } \\
\text { low the standard for the variety, } \\
\text { cut } 2 \text { points. }\end{array}$ \\
\hline
\end{tabular}

REASONS

\section{Kansas Score Card}

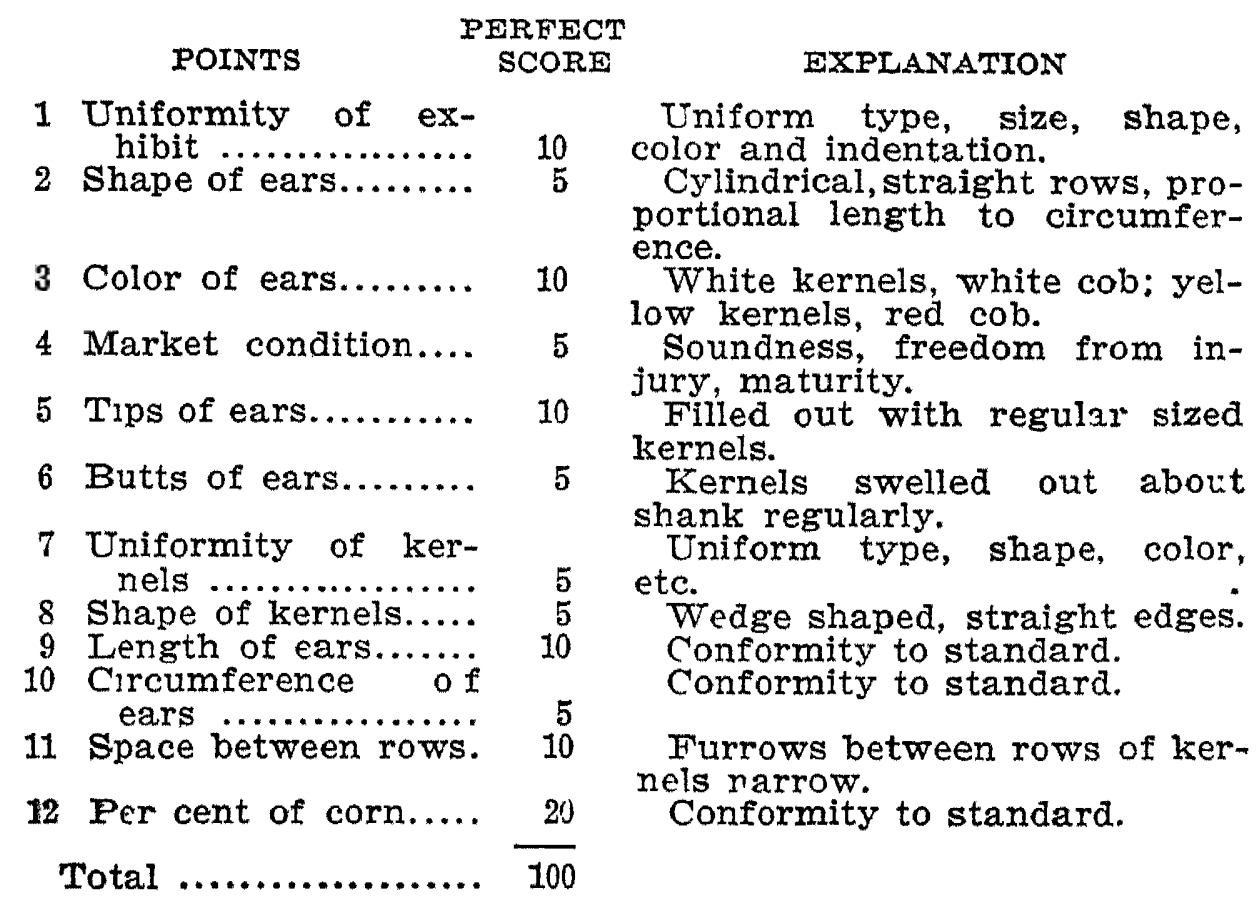

REASONS 


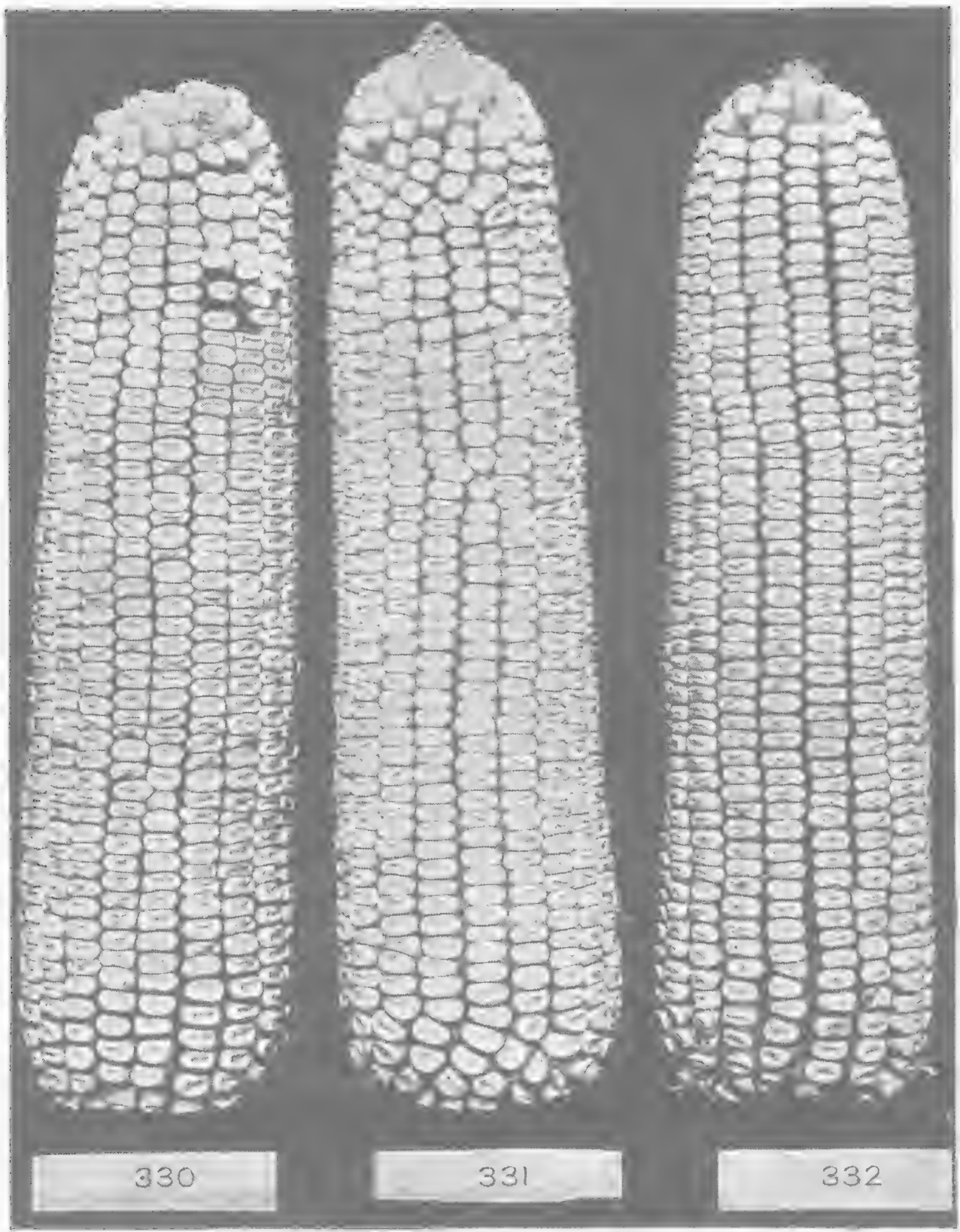

UNIFORM EARS-THE TYPE, SLOPE, COLOR AND INDENTATION ARE UNIFORM 


\section{IlLINOIS SCORE CARD}

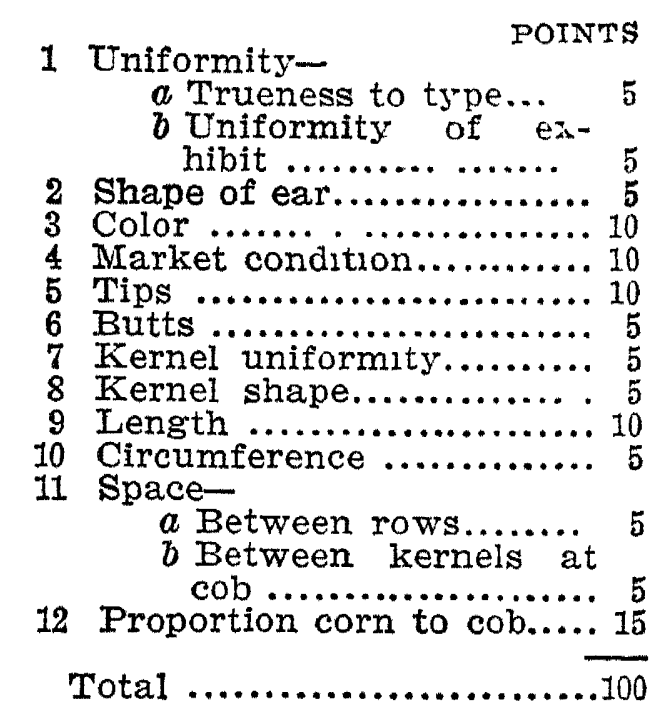

\section{Rules to be Used in Judanida}

1. The deficiency and excess in length of all ears not conforming to the standard for the variety shall be added together, and for every inch thus obtained a cut of one point shall be made. In determining the length, measure from the extreme tip to the extreme butt. The standard of length for the early maturing varieties shall be 9 to 10 inches. For the medium and late varieties 10 to 11 inches in length.

2. The deficiency and excess in circumference of all ears not conforming to the standard of variety shall be added together, and for every two inches thus obtained a cut of one point shall be made. Measure the circumference at one-third the distance from the butt to the tip of the ear. The standard of circumference for early varieties shall be 7 to 7.5 inches. For medium and late varieties 7.5 to 8 inches in circumference.

3. In determining the proportion of corn to cob, weigh every alternate ear in the exhibit. Shell and weigh the cobs and subtract from weight of ears, giving the weight 


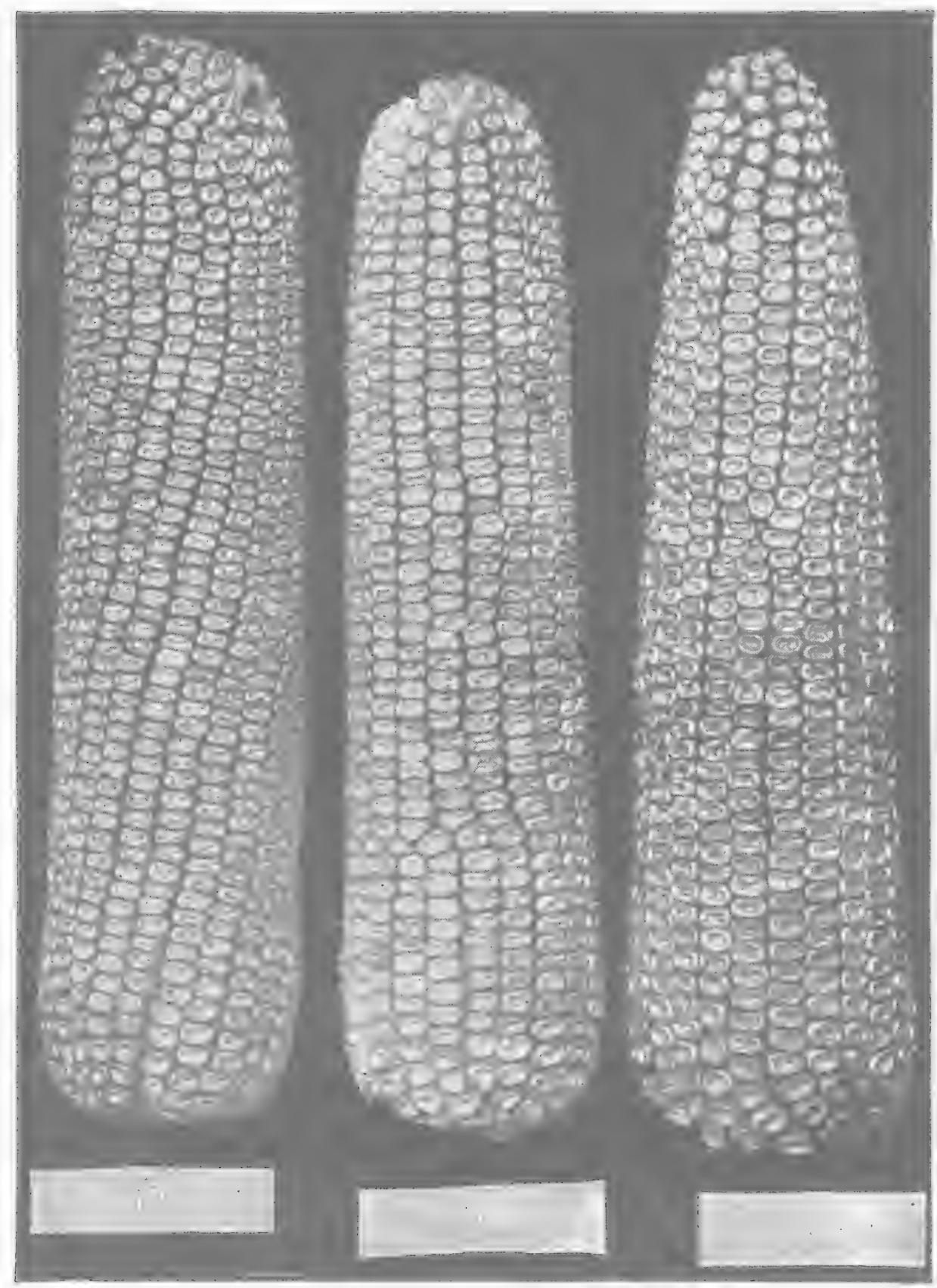

SLOPE OF EARS-101 OVITNDRTOAL, 102 PARTTY CYLIXDRICAI, 103 VERY TAPERING. YELLOW RACE 
of corn. Divide the weight of corn by total weight of ears, giving the per cent of corn. For each per cent short of standard for the variety a one point cut shall be made.

4. In judging color, a red cob in white corn, or a white cob in yellow corn, shall be cut ten points. For one or two mixed kernels a cut of one-fourth point; for three or four mixed kernels a cut of one-half point; for five mixed kernels, a three-fourths point cut, or for six or more mixed kernels, a one point cut shall be made. Kernels missing from the ear shall be counted as mixed. Difference in shade of color, as light or dark red, white or cream color, must be scored according to variety characteristics.

5. The furrows or angle between the top of the rows of kernels is the space between rows. The space between kernels on cob is determined by shelling off part of the kernels at middle of ear and noting whether kernels are pointed, leaving spaces between kernels, or moderately wedge-shaped and close fitting.

\section{STUDY OF CHARACTERISTICS}

In order to become accustomed to the points in judging a sample of corn, the following list of characteristics is given for the use of the person studying corn. By taking a sample of twenty-five ears of ordinary corn and studying each ear carefully, with this list for reference, each of the points mentioned may be brought out by example. This study is especially recommended for all persons wishing to become familiar with the characteristics of corn.

\section{Shape of Ear}

Cylindrical-Uniform in circumference from butt to tip. Partly cylindrical-Uniform in circumference for a portion of length. 


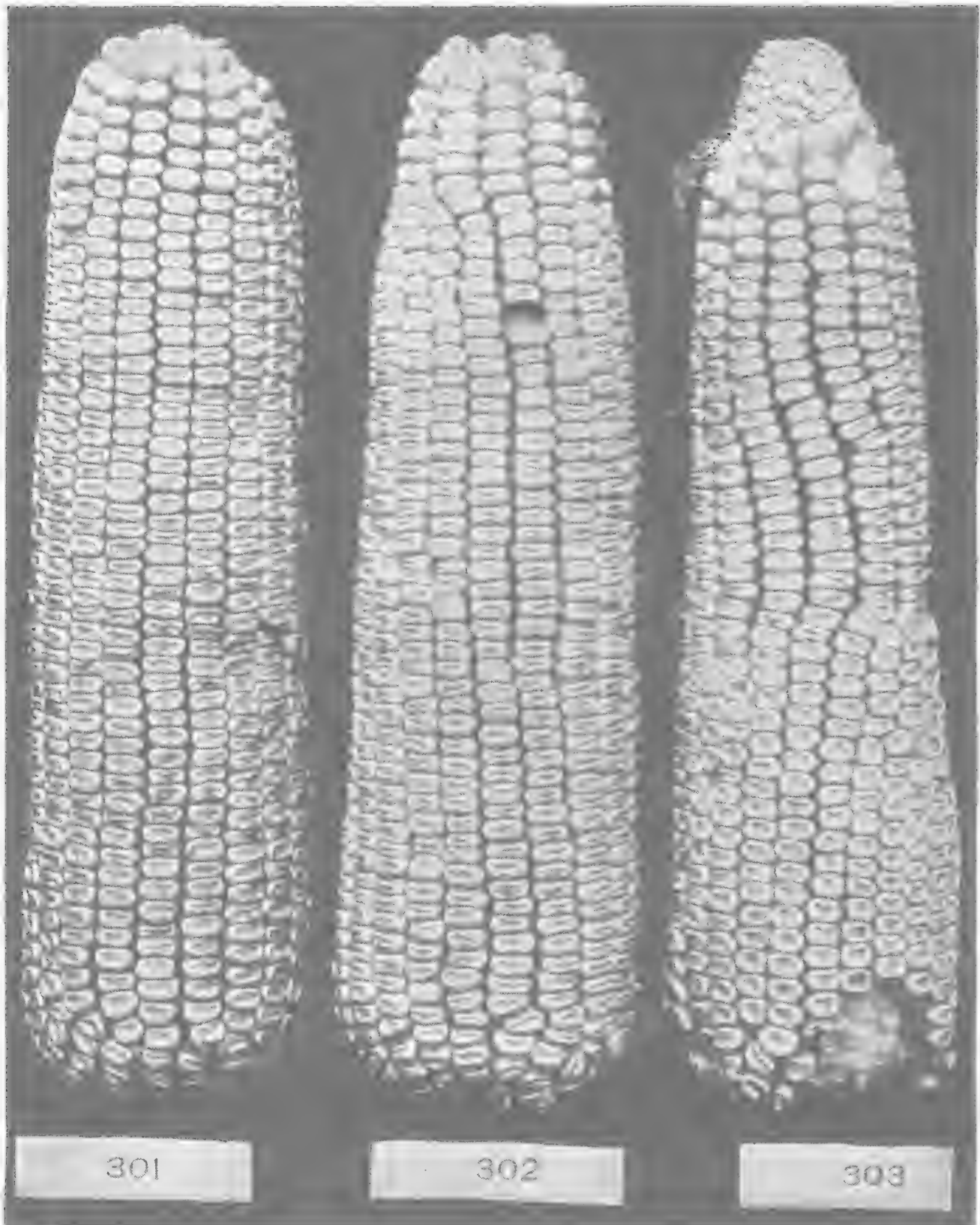

SLOPE OF EARS--301 CYLINDRICAL, 302 DISTINCTLY TAPERING, 303 VERY TAPERING. WHITE RACE 
Slowly tapering-Taper slight, regular.

Distinctly tapering-Taper very apparent.

Very tapering-Extremely tapering.

Too short for circumference; too long for circumference-Proper proportion of circumference to length is as 3 to 4 , or for medium varieties 7 inches to 10 inches.

Circumference of ear at butt; circumference of ear at tip-(Measure two inches from the ends.)

Length of ear-(Measure from extreme butt to tip.)

\section{Rows OF KERNELS}

Rows in distinct pairs-The spaces between alternate rows of kernels wider than the others.

Number of rows-Counted three inches from butt.

Rows lost-Disappearing after extending three inches or more from butt.

Narrow space between rows-Rows pressed closely together.

Medium space between rows-Distinct furrows.

Wide space between rows-Wide furrows.

Rows straight-Parallel with cob.

Rows turned to right; rows turned to left-Rows angle to right or left of a straight line from butt to tip.

\section{Butt of Ear}

Even-Entire end of cob exposed, with butt kernels at right angles to axis of cob.

Shallow rounded-Cavity at butt shallow, broad.

Moderately rounded-Cavity moderately deep, medium diameter.

Deeply rounded-Cavity at butt deep, small diameter. 


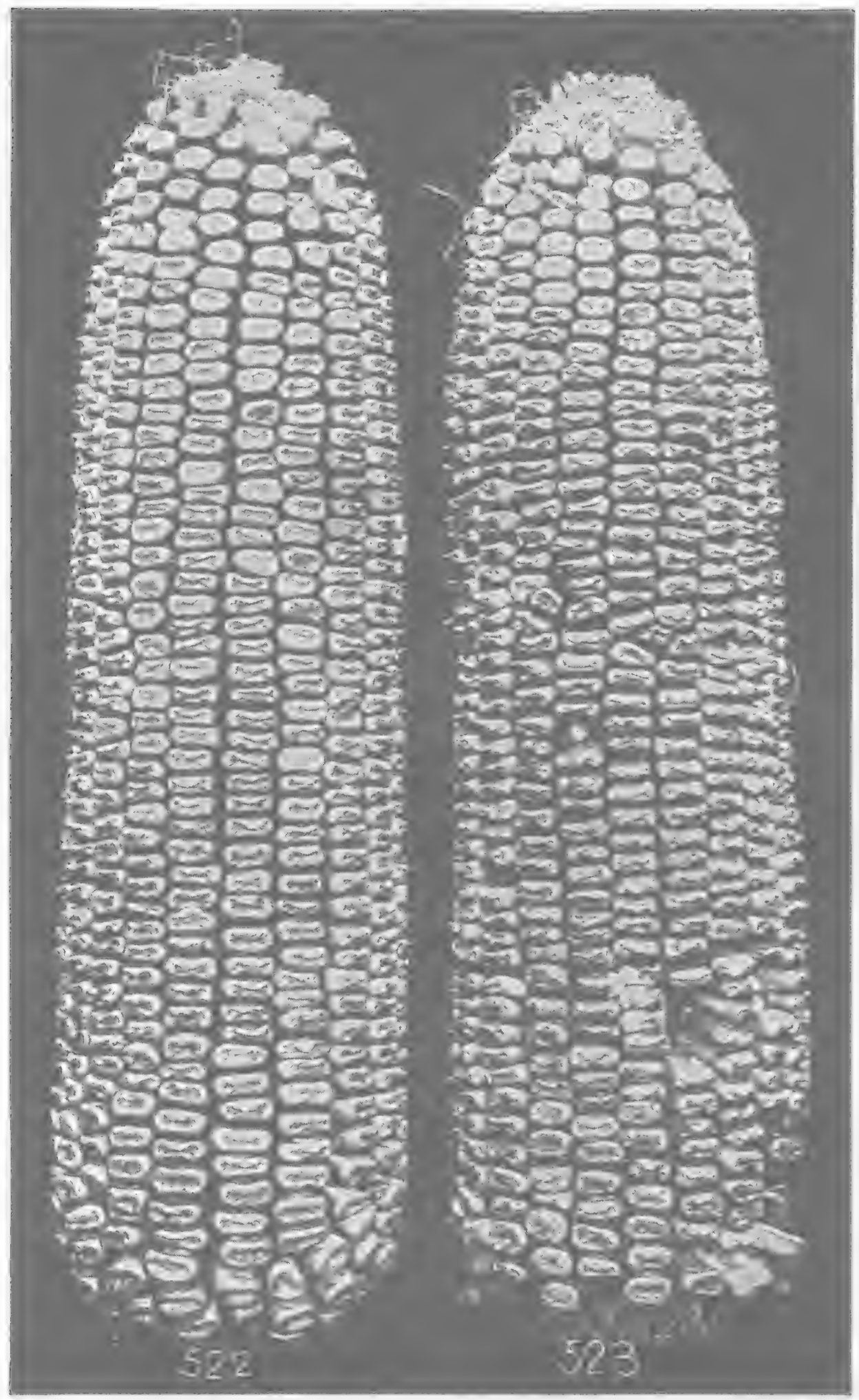

MARTET COADITION- 522 SOUND MATURE EAR, 523 CHAFFY 
Compressed-Cob rounded at end.

Enlarged-Large butt with no extra rows or kernels.

Expanded-Large butt caused by extra rows or kernels.

Open-Greater space between rows at butt.

Depressed-Kernels at butt flat, smooth and short, indicating a tight husk.

Kernels diverging-Space between summits of kernels in same row.

\section{Trp of EAR}

Kernels in rows-Rows may be traced to tip. Flat-Cob flattened at tip.

Filled-Entire end of cob covered with kernels.

Capped-A central kernel projecting from filled tip.

\section{KERNEL}

Firm-Rigid on cob.

Loose-Movable on cob.

Roof-shaped at one edge-Convex at one edge and flat at the other.

Upright-At right angles with surface of cob. Sloping-Leaning toward tip.

Overlapping at summit-As shingles on a roof.

Straight wedge-shaped-Edges of kernels straight, tapering.

Rounded wedge-shaped-Edges rounded lengthwise, tapering.

Square at top-Corners not rounded at summit.

Shoe-peg form-Long, narrow kernel holding size to tip.

Rounded corners-Corners rounded at summit and base.

Rectangular-Short and broad, as broad at base as at summit. 


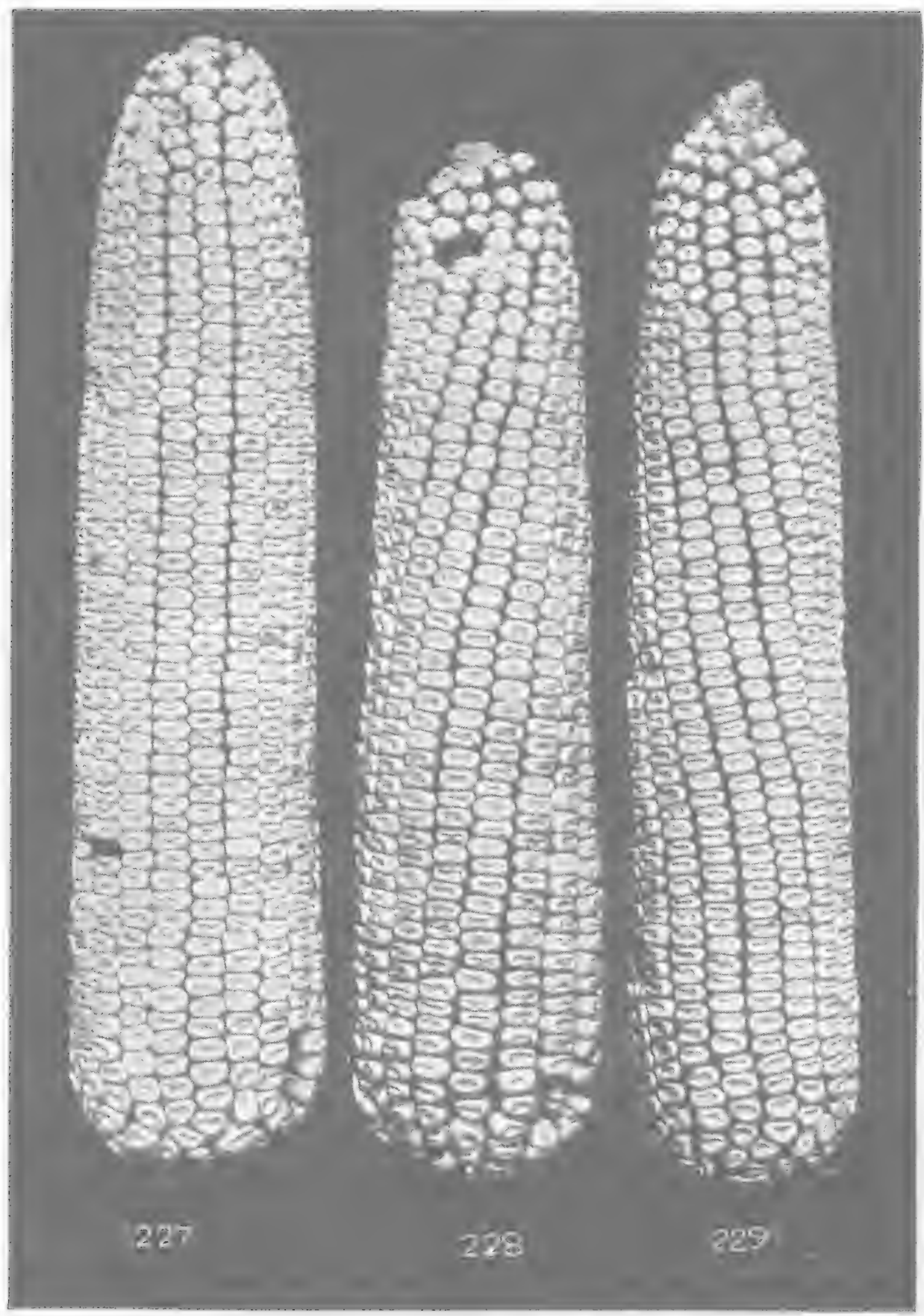

ARRANGEMENT OF ROWS-227 STRATGHT, 228 TURN TO RIGHT, 229 TURN TO LEFT. WHITE RACE 
Beaked-With long, sharp, tapering projection.

Slightly sharp point at summit-Pointed projection from chit side of kernel.

Small sharp point at summit-Pointed projection from shit side of kernel.

Round smooth dented-Round smooth depression at summit of kernel.

Long smooth dented-Long smooth depression.

Crease dented-Edges of kernels pressed toward each other, leaving small space between, and edges parallel.

Pinch dented-Edges of kernels pinched closely together.

Rough projection dented-With any rough, ragged or beaked projection from summit of kernel.

Bridge dented-Crease dented with fold across center.

Crumple dented-Seed coat wrinkled as in sweet corn. Breadth; depth; thickness-(Exact measure.)

Color-(Note shade.)

\section{SHANK}

Large-Nearly the diameter of cob.

Medium-Half the diameter of cob.

Small-One-third the diameter of cob, or less.

$\mathrm{COB}$

Large-Larger than $41 / 2$ inches in circumference.

Medium-From $31 / 2$ to $4 \frac{1}{2}$ inches in circumference.

Small-Not more than $31 / 2$ inches in circumference.

Color-(Note shade.)

In the following matter the amount of cut for each point is based upon the arrangement of the Indiana score card. In the cases of the other score cards with different 


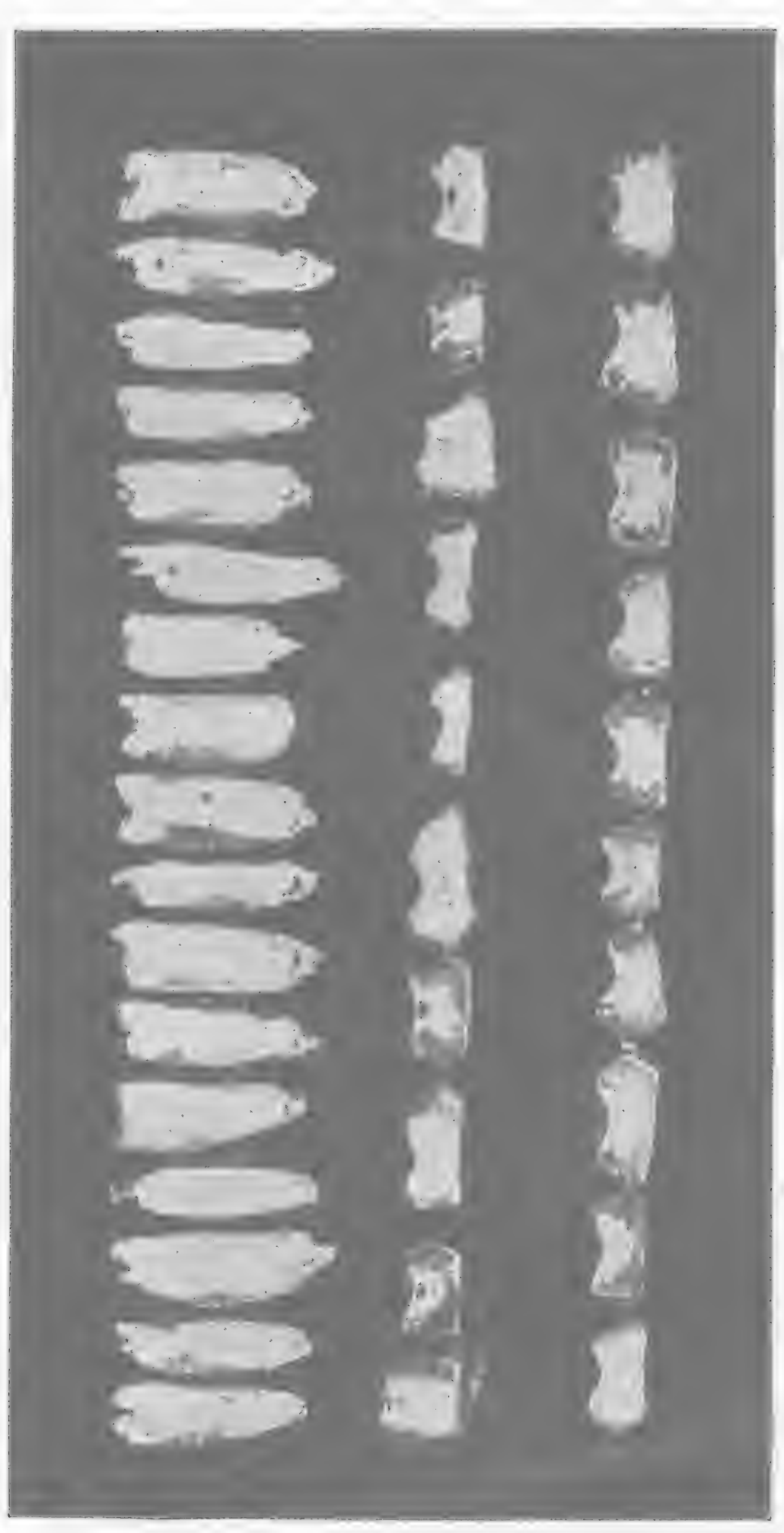

$+3$

E

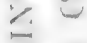

$\div$

0

$\cong=$

$\pm$

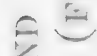

3

$=\frac{1}{5}$

实

$\therefore \frac{\pi}{2}$

空

政

e

崀葛

$\dot{5}$

空

$\frac{1}{12}$

$\approx$

浞

ㄴ.

芋

ㄴ.

을

5 -

o.

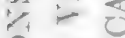

$\stackrel{9}{\circ}$

$=\frac{9}{5}$

\%

$\therefore$ 둔

$\div$.

힙

다웅

$E$

莎

$=\% 5$

$\div 0$

35 잉

$\infty 21$

然

६ิ 
arrangements, this difference must be taken into consideration. As the principles of scoring are the same under all conditions, it can be seen that the amount of cut on each point can easily be adapted to any score card. In most cases definite directions are given in each score card differing from the Indiana arrangement as to the amount of cut for each point.

\section{THE WORK OF SCORING}

Following is a discussion of the points in the score card, each point being taken up in detail.

\section{UNIFORMITY OF SAMPLE}

By uniformity is meant uniform ears having similar size, shape, color, indentation, breed characteristics, etc.; in fact, all points which go to make up an ear of corn. The ears of the sample should possess similar or like characteristics, but the kind of shape or other characteristics is not taken into consideration at this time. The most important feature of this point is breed characteristics; in other words, the characteristics which enter into the distinguishing of one breed from other varieties or races. It is impossible to define these characteristics, and experience with the different standard races is about the only guide in determining the purity of the sample as regard race standards. There are distinct lines between the races of corn by which we know that a characteristic sample is Boone County White or Silvermine, or Leaming or other races, but it is only by familiarity in handling a large number of samples of these types that these lines can be distinguished.

The ears should present a uniform appearance. This point is one of the most difficult to be properly estimated. In the beginning actually rearrange the exhibit, if neces- 


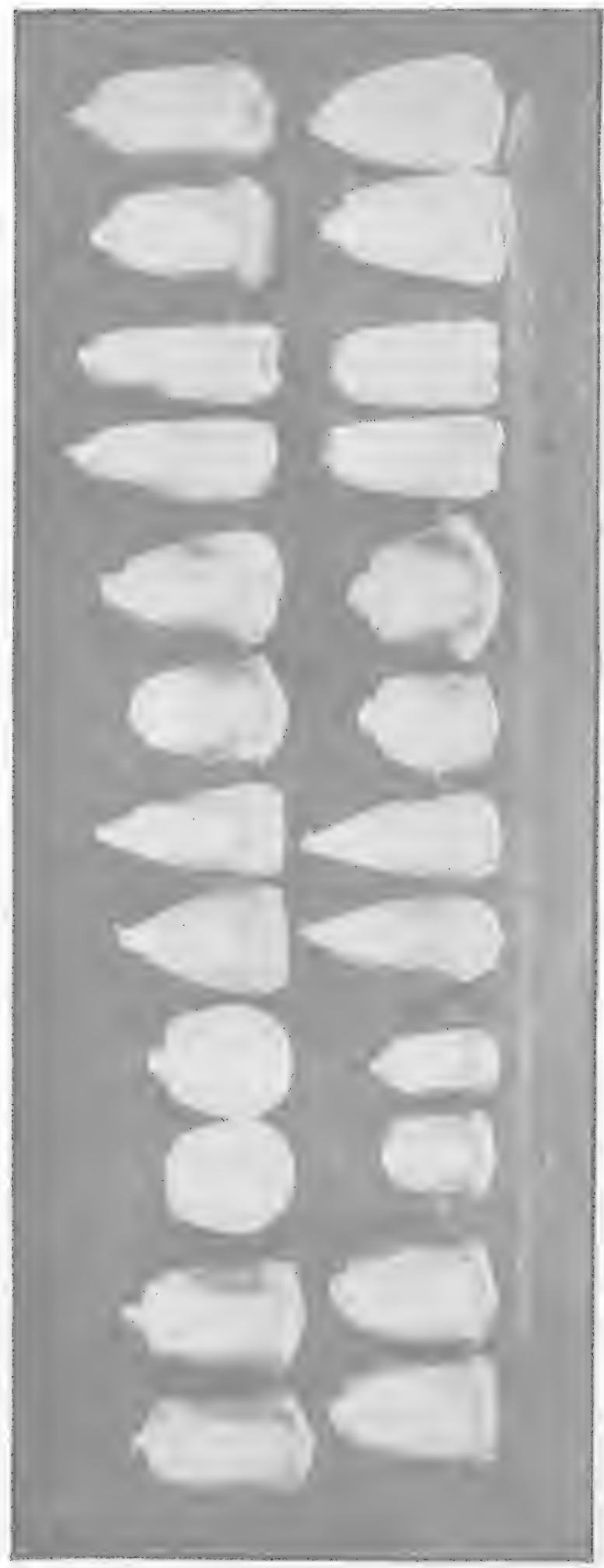

क्. 
sary, and place the uniform ears together. In this way a better idea can be gained of the uniformity of the exhibit and of the value of this point. If, for example, six ears in the exhibit are fairly uniform and four are distinctly different in general type, a cut of four points should be made. In other words, give the sample a marking of six points. This plan will give a just marking, because, although the six ears may not be absolutely uniform, the four ears are not entirely dissimilar. The shape should be uniformly the same in the different ears of the exhibit. The shape may be very poor, but if the ears are alike they must be counted of uniform shape. The size may be too large, but if all the ears have the same size and type the exhibit will be uniform and no cut should be made in the score. It is usually an easy matter to divide an exhibit into the uniform and non-uniform ears where there are distinct differences, but the cases of slight differences must be cut according to the best estimate of the judge.

\section{Shape of EARS}

In shape the ear must be true to variety shape. For instance, the shape of the Boone County White ear is cylindrical, while that of the Leaming is slightly tapering. Each variety has individual variety peculiarities of shape. In general, all ears should be cylindrical, carrying the same circumference from the butt to the tip. This shape will secure uniform sized kernels from butt to tip. Consequently there will be a larger proportion of corn to cob in such cylindrical ears than on very tapering ears. In most tapering ears the taper is caused by the dropping of one or more rows of kernels about one-third the distance from the butt to the tip. These dropped rows cause irregular kernels, a smaller proportion of corn to cob, and a poorly shaped ear. The rows of kernels must be straight and 


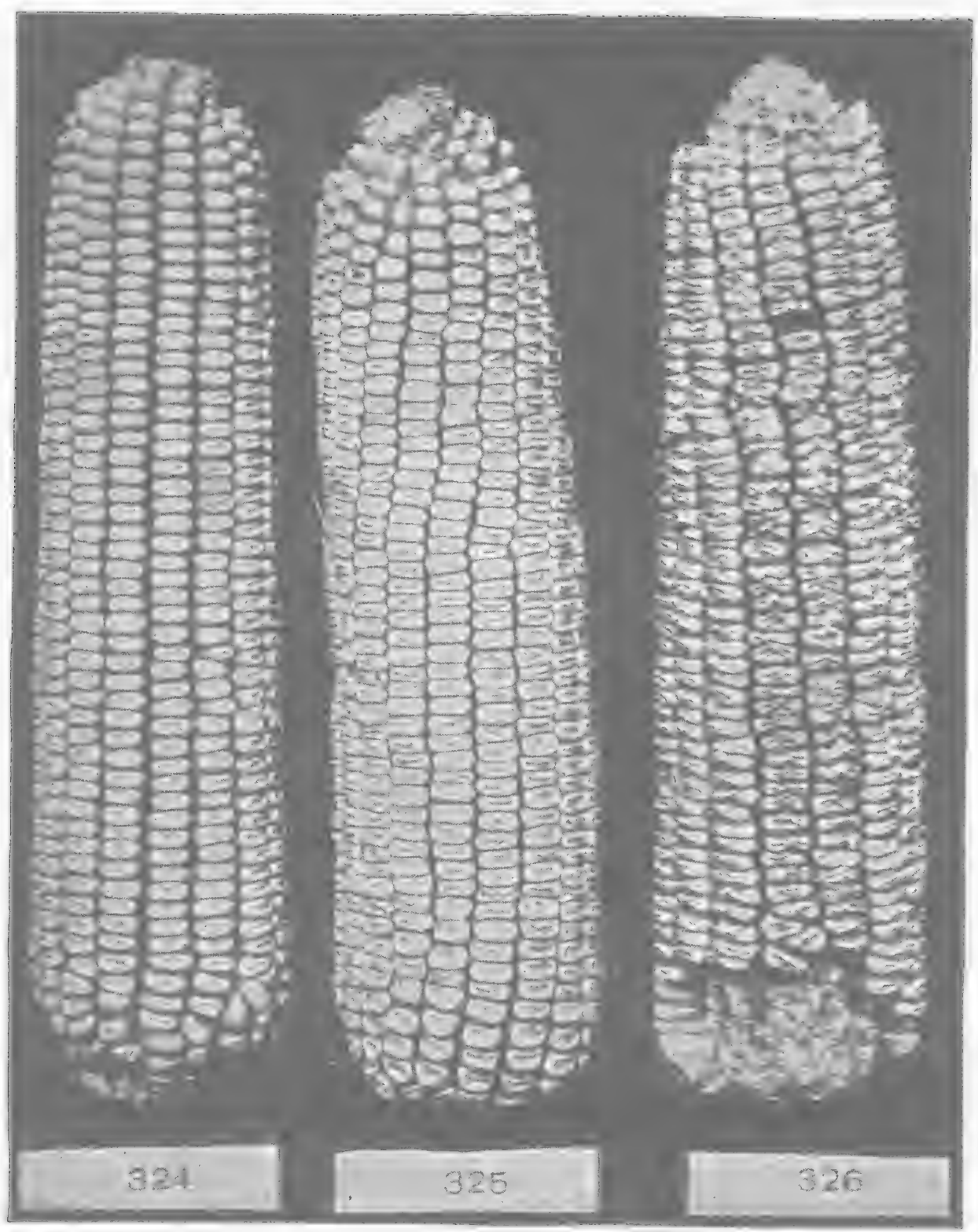

INDENTATION-324 SMOOTH, 325 MEDIUM, 326 ROUGH. WHITE RACE 
parallel with the cob. If the rows turn to right or left, or are irregular and crooked, such irregularity must be taken into consideration and a cut made in accordance with the experience of the judge. In judging shape count the number of well shaped ears true to variety type in the exhibit and the number of poorly shaped ears. Cut according to the proportion of poorly shaped ears, e. g., for four poorly shaped ears, cut the exhibit two points. The scoring of shape is a matter of experience, and cannot be determined by any set rules. The shape which is most desirable in one case may be undesirable in others. It is well to keep in mind that the ears should be of such shape that they will mature under the climatic and soil conditions in which the race is grown, and will admit of the development of the largest possible weight of shelled corn of the most valuable quality. It is possible that consideration of fancy shapes may lead to the development of unprofitable types, therefore it is important that the judge realize the relation between shape of ear and the value of the ear. There seems to be no good reason why ears of corn with rows of kernels around the cob instead of parallel with it, as is usually the case, may not be as desirable as the straight rows. If there was found any advantage in yield or other points in the case of the ears having round rows, other things being equal, the round rowed types would be most desirable. However, we believe that the straight rows permit of the development of the greatest weight of shelled corn, therefore we give the ears having straight rows the preference at present.

\section{CoLOR OF EARS}

For all recognized varieties white corn should have white cobs, and yellow corn red cobs. If a yellow sample contains a white cob, or a white sample a red one, 


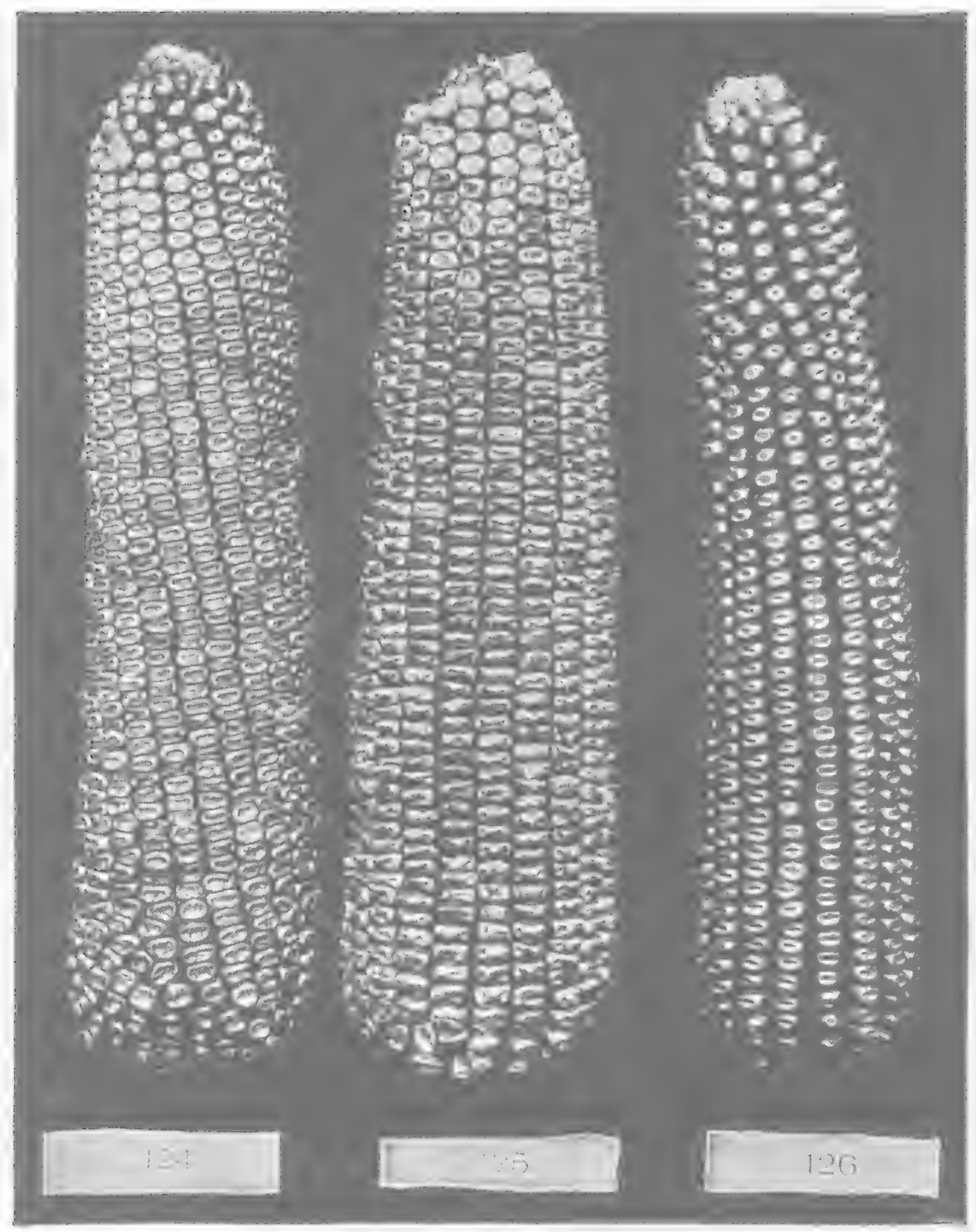

INDENTATION-124 MEDIUM, 125 ROUGH, 126 SMOOTH. YELLOW RACE 
it is an evidence of very careless selection and should bar the sample. A zellow kernel in a white ear, or a white kernel in a yellow ear, is an evidence of mixed corn.* In other words, in the case of the yellow kernel in the white ear a stray pollen grain from a yellow variety has fallen on a silk and fertilized a kernel of white corn. Single mixed kernels in an ear show merely accidental mixture, and if the ear is to be used for seed the mixed kernels should be removed to prevent it from effecting further mixture the next year. In looking for mixture the tips and butts of the ears must be closely examined. The young ear ripens silks on the butt first, the middle of the ear next, and the tip last. If the butt silks should ripen so early that the pollen of that variety is not ready to fertilize them, they will either not be filled out or will be fertilized by the pollen of some earlier variety which may be growing in the vicinity. As frequently happens, the tip silks may not appear until the pollen of the variety is gone. In this case the tip may either not be filled out or may le fertilized by pollen of some late variety, thus causing mixture. If the mixture is between yellow and white corn, it can be seen in the yellowish cast of the white kernels or the whitish cast in the yellow kernels, particularly in the so-called "White Cap."

For one or two mixed kernels in an ear a cut of .25 point should be made. For three or four mixed kernels cut .5 point; for four or five such kernels cut .75 point and for more than five cut one point. All missing kernels may be assumed to be mixed kernels; and in exhibits in corn shows a cut of .1 point should be made for every missing kernel.

\section{Market Condition}

By market condition is meant ripeness, soundness, freedom from injury or disease, and brightness of color. In

\footnotetext{
*Bulletin No. 22, Vegetable Physiological and Pathological Investigations, $U$ S Dept Agri. 1900. (Every corn student should read this bulletin carefully)
} 


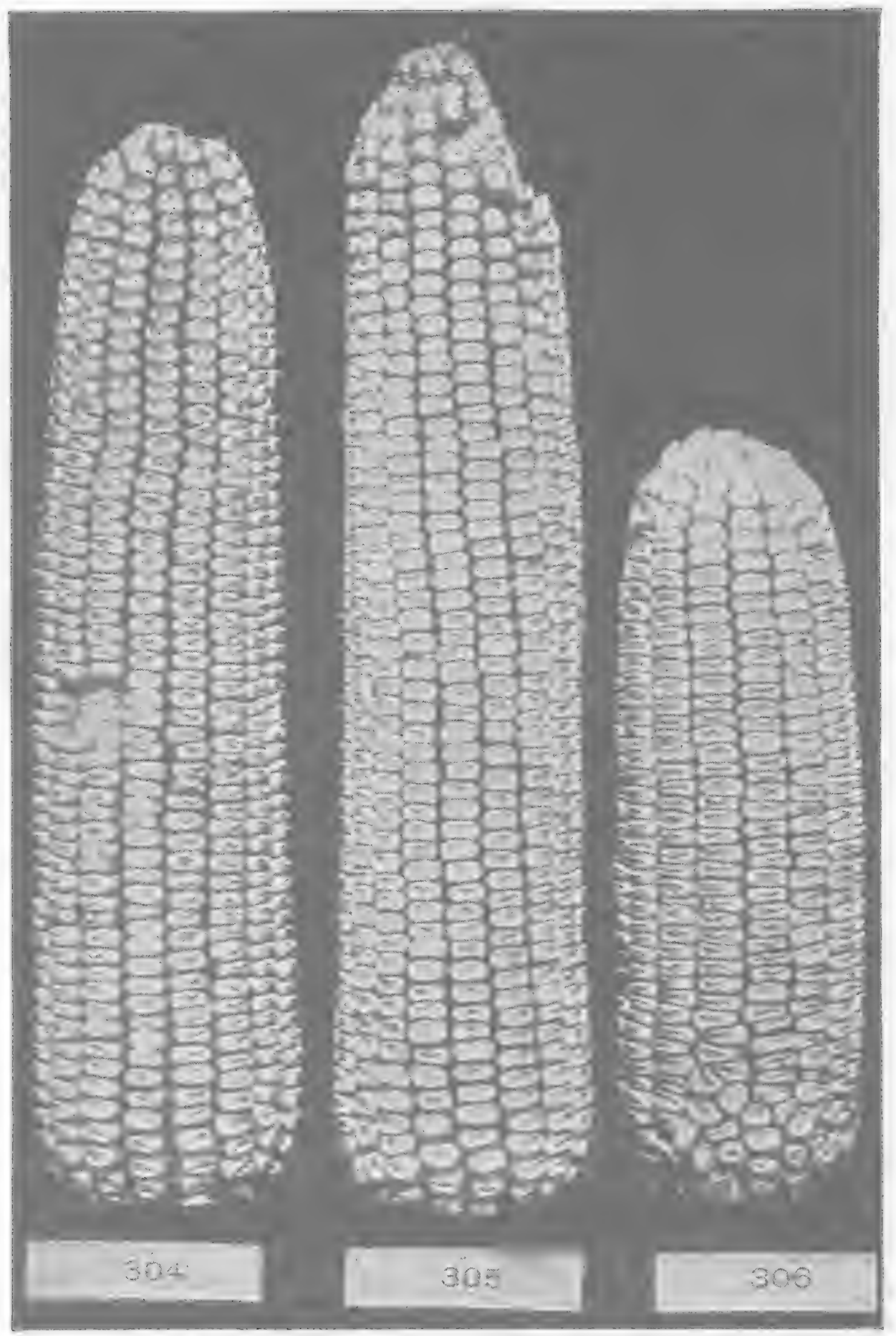

IEXGTH OF EARS-304 PROPER IEXGTH, 305 TOO TONA 306 TOO SHORT 
other words, the condition of the ear best adapted for marketing. In corn exhibited in the "show ring" market condition is usually found by the looseness of kernels on the cob. This condition indicates the degree of maturity. In drying out, the kernel shrinks, leaving it loose and movable on the cob. In an immature ear the season is not long enough to enable the plant to store the starch, protein, oil, etc., in the kernel to its full capacity. Consequently as the excess of moisture dries out it leaves the walls or coats of the kernels without being fully packed. Such kernels are frequently called "chaffy."

Testing Vitality of Seed Corn-There is no means of testing the vitality of seed which properly comes under market condition, except by a germination test. In selecting seed corn it is very important that a thorough test of the vitality be made. This can be most easily and satisfactorily done ky taking three kernels out of every ear to be tested, one from near the tip, one from the middle and the other from near the butt of the ear. Fill an ordinary plate about two-thirds full of fine sand. Pour water over the sand until it runs off the plate. Tip the plate at an angle of about 45 degrees, and allow the water to drain off a few minutes. Now plant the kernels of corn point down in the sand and barely cover with sand. Make a careful count of the kernels put in each plate and keep an accurate record of the number. Now turn a slightly smaller plate over the plate of sand to prevent too rapid evaporation of moisture and set in a warm place. Examine every day and keep the sand moist. At the end of ten days all the kernels should have germinated. Count the kernels that have sprouted and compute the per cent of germinating kernels. In seed corn 97 per cent germination in five days constitutes the standard of vitality.

In scoring maturity take each ear up carefully and give it a sharp twist. If it is mature it will remain firm and 
solid. If immature it will twist loosely about in the hand. Count the number of immature ears and cut the exhibit one-half point for every diseased, chaffy, immature ear. For instance, if there are six immature ears cut the exhibit three points, or give it a marking of two on market condition. In the cases where the corn samples must be harvested unusually early in order to be sent to the exhibit, as at fairs hold early in the autumn, the ears will not have dried out, and consequently will be immature. In such instances the judge must take this condition into account and score on a uniform comparative basis. In the study of market condition, the per cent of moisture in the samples, the number of diseased and injured kernels, together with the amount of all bits of silks, husks or other debris, is carefully and accurately determined. Such tests may not be practical in the actual process of judging samples, but all corn judges should become familiar with these tests in order to train the mind to take these conditions accurately into account in scoring on market condition.*

\section{Tirs of EARS}

The tips of the ears should be filled out with regular uniform sized kernels. No portion of the cob should project beyond the kernels. If the cob does extend beyond the kernels it shows that the tip kernels have not been properly developed. As the tip silks mature last on the ear, it is natural that frequently the tip will mature so late that all of the pollen will have gone by the time the silks of the tip kernels are ready to be pollinated. In such cases it will be found that the silks on the tip will keep growing for an abnormal length of time, providing an opportunity

\footnotetext{
*Bulletin No. 41, Botanical Investigations, U. S. Dept. Agri., 1903. (This bulletin contains a full explanation of these tests and should be used as a guide in carrying on this work.)
} 
for late fertilization. In many cases the tip kernels are irregular in size. This is due to partial or irregular development, part of the kernels having been fertilized and part unfertilized, or part of them having been fertilized much later than others. The fertilized kernels swell out into irregular shapes and sizes in an effort to occupy all of the space. If the tip is not fully filled out it is an evidence of some irregularity in development, and it should be marked accordingly. For every exposed tip one inch long make a cut of one point. For less exposed tips make smaller cuts, even down to one or two-tenths. In the case of irregular kernels on the tip the judge must mark according to the degree of irregularity. The rows of kernels should extend in straight regular order over the tip.

It is a matter of common experience that more well filled tips are developed in favorable seasons than during unfavorable conditions. It is also true that races having characteristically short ears are likely to have better filled tips than races having large, long ears, grown under similar conditions. It is absolutely necessary that we keep in mind the fact that we are selecting those samples which will tend to grow more corn per acre, and if long ears not covered over the tips with kernels give the largest yield, this type is most desirable and should be scored accordingly. The $c o b$ is an axis bearing the kernels, and the larger the cob, other things being equal, the more kernels can be developed on each ear. However, as between two ears of the same size, grown under similar conditions and for like purposes, one having the tip fully covered with uniform, regular kernels, and the other having the tip uncovered, the covered tip is certainly the most desirable: In most cases where the tip is uncovered, the kernels near the tip are small, irregular and in every way undesirable. Therefore these uncovered tips should be cut severely, more so than if all the kernels were of the 


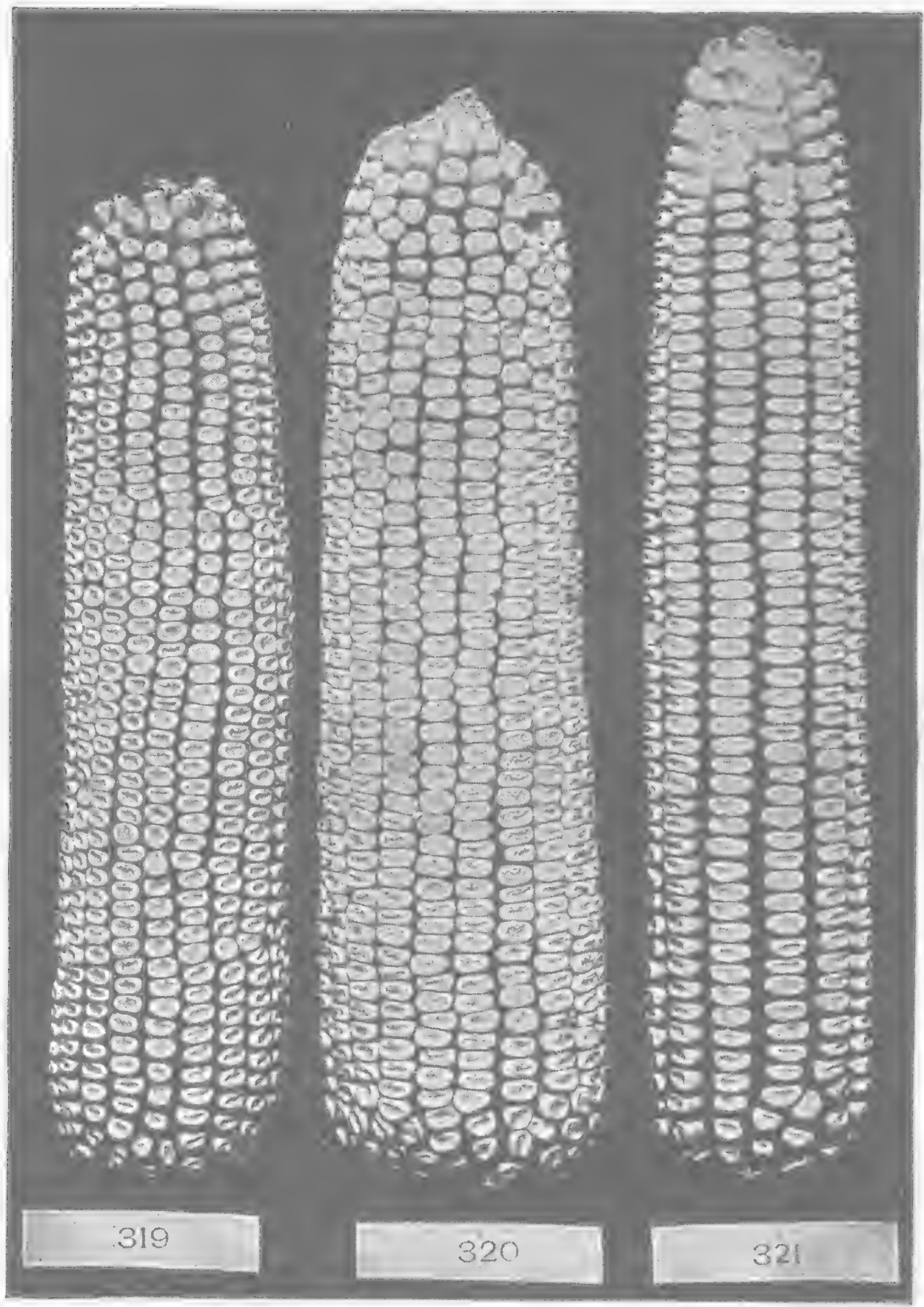

CIRCUMFERENCE OF EARS-319 PROPER CIRCUXFERENCE, 320 TOO LARGE, 321 TOO SMALL 
regular uniform size and shape. It is necessary for corn judges to study tips of ears under different conditions in order to gain a safe point of view from which they can properly score the filling out of the tips.

\section{Butts of EARS}

In the case of the butt the rows of kernels should extend in regular order over the butt and around the shank or ear stalk. When the shank is removed in husking, a regular depression should be left. If the kernels are not filled out about the shank, the shank is usually developed very large and strong. This interferes very seriously in husking, as it is very difficult to break off some of the heary shanks. Not only is this true, but in such cases, the butt of the cob not being fully filled over, there is a smaller proportion of corn to cob. This filling out about the shank can be carried too far, as many other single points may be developed out of true proportion. In one of the standard varieties it is not infrequent that the ears break off in the fall before husking. In other words the shank is not large enough or strong enough to support the weight of the ear. Upon examination of such ears the butt will be found to be so completely filled out that the shank has been dwarfed. The shank has been bred so small that in a heavy wind the swinging of the ear back and forth on the stalk breaks the ear off from the shank at the butt. A large butt poorly filled out is usually accompanied by a large cob. This cob will usually be found to be very sappy at the time of harvest. This is a great detriment to the ear of corn, not only in loss of grain, but from the fact that such ears are easily affected by changes of temperature. The cold weather freezes the water in the cob and kernel, and thus expands and bursts the cell walls in the germ. This may reduce the vigor or destroy the life of the embryo plant. 
In the case of the butt the silks occasionally mature so early that there is no pollen ready for the fertilization of the butt kernels, although in most varieties the pollen matures before the siiks. Therefore we find a large proportion of good butts more frequently than good tips.

In showing corn it is very desirable to trim out with a knife all traces of the ear stalk. This will add to the appearance of the exhibit in a perfectly legitimate way. In fact, this grooming of the ears should be carefully attended to by the exhibitors, as a little attention will frequently add considerable to the scoring of the exhibit.

The size of the depression in the butt of an ear will depend on the variety. In a large variety, as Boone County White, it will be larger than in a smaller eared variety, as Riley's Favorite. This characteristic must be taken into account by the judge through familiarity with the breeds of corn.

In scoring butts a very poorly filled butt in which the kernels do not cover the end of the cob should be cut .5 of a point. If the kernels cover the cob, but are flat, shallow and irregular, cut .3 of a point. If the kernels are regular in size, but do not swell out beyond the cob, cut .2 of a point. In the case of kernels swelling out beyond the cob in an irregular manner cut .1 of a point. If the kernels are swelled about the shank in regular manner, leaving concave depression, give full markung.

\section{UNIFORMITY OF KERNELS}

The shape of the kernel will depend somewhat on the variety. Whatever the shape of the kernel in an exhibit, it should be uniform. The size of the kernel should be the same in all of the ears. To examine kernel uniformity take out two kernels with a knife from each ear about one-third the distance from the butt to the tip. Lay 
them directly in front of the ear with tip of kernel pointing toward the ear. In this position the comparative shape, size, etc., can easily be noted by the judge. The judge should note the ears to see if the kernels are uniform in all parts of the ear. For instance, if the ears are rough, note that all the kernels are rough, or vice versa. A rough kernel usually indicates a deep kernel. In dent corn the tip of the kernel is first packed with food for the use of the young plant and matures first. As the season advances the rest of the kernels fill and mature. The seed coats of the kernel are developed far in advance of the development of the food in the kernel. As the grain approaches maturity the kernel dries, hardens and contracts, and the seed coat at the top of the kernel is drawn down into stored up food. This is the cause of the indentation. The deeper the dent, the greater liave been the possibilities of development of the depth or length of the kernel.

Count the number of ears having generally uniform kernels and mark in proportion to the number of uniform kernels. For instance, if there are five sets of uniform kernels, and the ears from which the samples were taken have uniform kernels, mark the samplo 2.5 points for uniformity of kernels. Of course the five ears that have been counted as uniform will not be absolutely uniform, neither will the other five ears be non-uniform, and the proportion will about average up the true value of the sample on this point.

\section{Shape of Kernelis}

The shape of the kernel will vary with the variety. However, in general, the kernels should be wedge-shaped. This wedge shape permits the greatest possible amount of grain to the cob. The tips of the kernels are set on the 


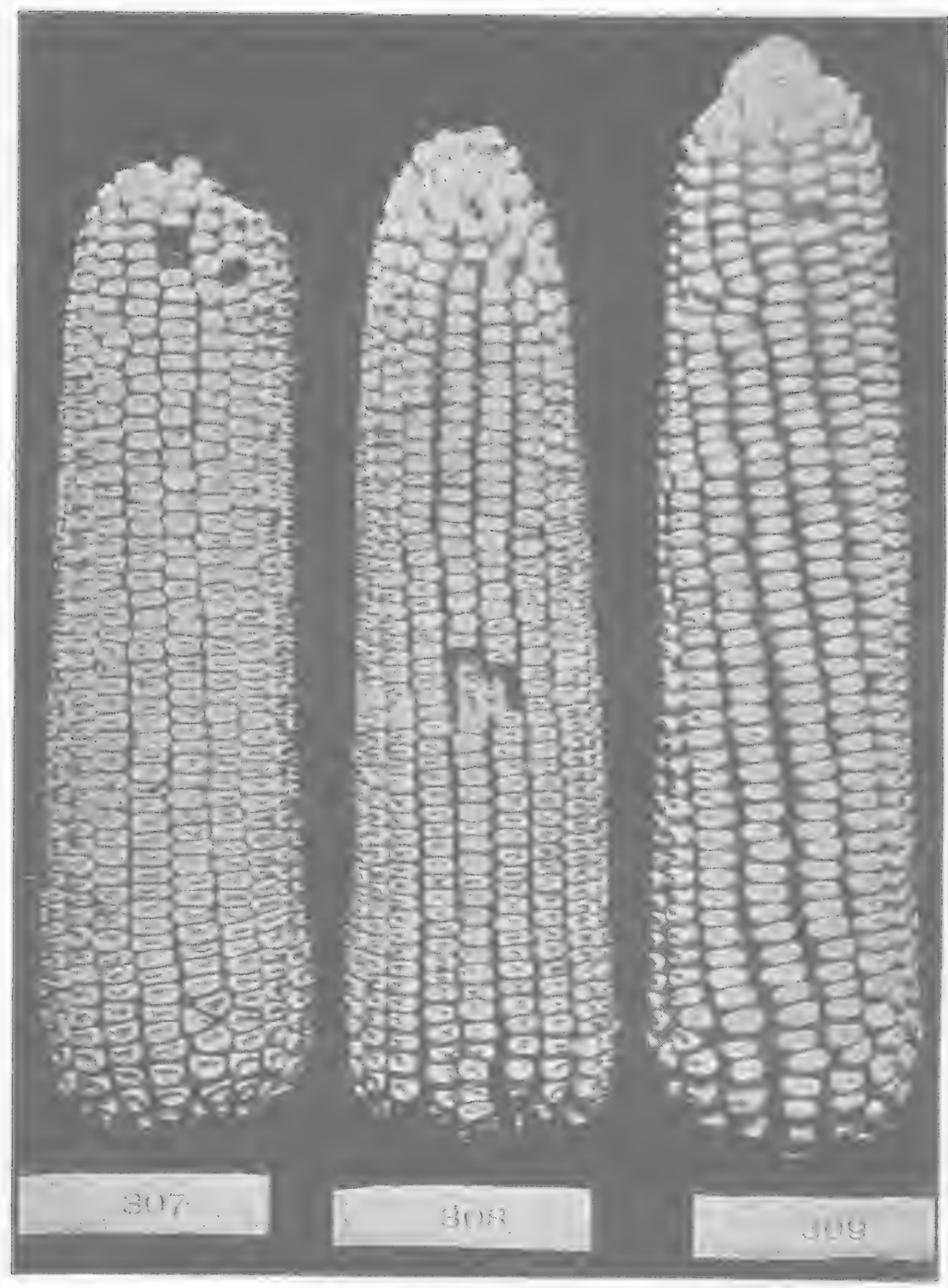

SPACE BETWEEN ROWS- 307 KARROW, 308 MEDIUL, 309 WIDE 
cob in regular manner. In order for the rows of kernels to fit snugly together from the point to the crown it is necessary to have a wedge shape. It is also necessary that the edges of the kernels be straight. Otherwise the middle of the kernels would touch and there would be furrows or spaces between the tops of the rows. This is so true in practice that we find ordinarily in the wedge-shaped kernels that there are from 18 to 24 rows cf kernels on the cob. But in the case of broad, rectangular kernels or kernels with rounded edges we find from 12 to 18 rows of kernels. In other words, with the wedge-shaped kernels the greatest proportion of corn to cob is found.

It has been found that there is a correlation between the shape of a kernel and the composition. For instance, a kernel having a thin tip is usually low in per cent of oil and protein and high in per cent of starch. It is usually true that such pointed kernels are low in vitality or lack constitution, if such a term is admissible aswapplied to the vigor of growth in corn. The most desirable shape, then, as a rule, is plump tips having about the same thickness as the upper portions of the kernel. The thin pointed kernels usually result in space between the tips of the kernels as they set on the cob, an undesirable condition. Naturally the width of the kernel decreases from the crown to the tip in order to allow the kernels to fit suugly together on the cob. It is desirable to have this slope developed to the point where the sides of the kernels evenly touch the sides of the kerncls in the adjoining rows. If the slope is very sharp it ends in a pointed kernel, space occurring between the sides of the kernels near the cob. This condition results in a loss of a valuable portion of the kernel, usually in comparatively small germs, therefore reduces the value of the ear of corn. Such kernels are usually referred to as round-pointed kernels, and by breaking an ear of corn possessing this type of kernels into two or more pieces, and looking at the end sections, these 
spaces can easily be seen. From the fact that the kernel is the unit of the grain on the cob, it is at once evident that it is extremely important to secure the kernel of the proper shape, proportionate to its size, and develop uniform kernels of this type on the entire ear. The desirable type of kernel for every type, as in the case of the breed characteristics, is a matter of experience which must be gained through familiarity with all types.

In judging. shape of kernel, count the number of wedgeshaped kernels in the ten pairs that have been taken out for study of uniformity. Mark according to the proportion of well shaped kernels. For instance, if there are eight pairs of properly shaped kcrnels, mark the exhibit four points on shape of kernels.

\section{LENGTH OF EARS}

The deficiency and excess in length of all ears not conforming to the standard for the variety should be added together, and for every inch thus obtained a cut of .5 point should be made. In determining length measure from the extreme tip to the extreme butt. In measuring length it is most convenient to hold a foot ruler in both hands, one end even with the butt and the other end over the tip. As the ruler is drawn from ear to ear in the sample, it is an easy matter to keep in mind the amount each ear is shorter or longer than standard. Add the excess and deficiency together.

\section{Circumference of Ears}

The excess and deficiency of all ears not conforming to variety standard should be added together, and for every inch thus obtained a cut of .25 point should be made. In measuring circumference use a tape line. Measure the circumference at about one-third the distance from the butt to the tip of the ear. In order to do this conveniently 
and with the least possible loss of time pick up the ear in the left hand. Hold the end of the tape line on the ear with the index finger of the left hand at the necessary point. Now quickly wrap the tape about the ear and note the measurement, adding together the excess, or the lack of proper circumference for each ear, and cut according to rule.

Another method of measuring the circumference is to measure the circumference of the ear about two inches from the butt, and then about two inches from the tip. Add the two measurements together and divide by two, the resulting figure being the average circumference of the ear. The disadvantage of this system lies in the time necessary to make the extra measurements and the computations. Its advantage is that it takes into consideration the tapering of the ear in considering the circumference. In view of the fact that a trained judge naturally scores on this point under shape of ear, the desirability of this method is questionable.

\section{Space Between Rows}

The first kind of space between rows is the furrow between the top of the rows of kernels. It is usually greatest in broad, shallow kernel or a smooth kernel type of corn. To determine the cut for space the following rules can be applied if tempered with the judgment of the scorer: For less than 1-32 inch, no cut; for a furrow 1-32-1-16 inch in width, one-half point cut; for more than 1-16 inch, cut one point for each ear. This space between rows may be a relic of the early type of Indian corn. It indicates a reversion to the unimproved varieties and is very undesirable. It is usually accompanied with a comparatively small number of rows of kernels on the cob, and consequently a small proportion of corn to cob. 


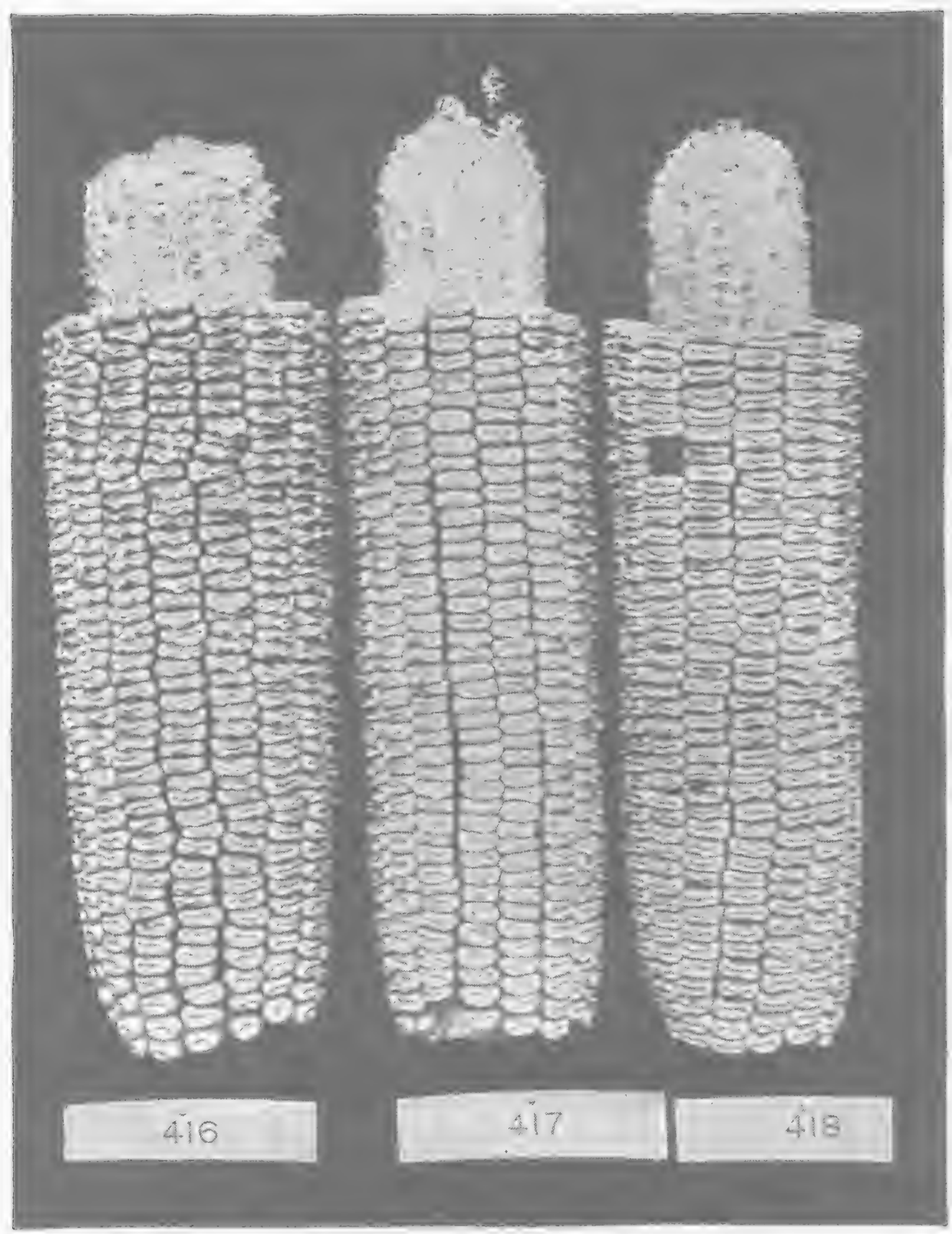

STZE OF COB- 416 LARGE, 417 MEDIUM, 418 SMALL 
The second kind of space between rows is the space between kernels at the tip about the point where the kernels are attached to the cob. In order to examine the ear for this point it is probably necessary to shell off a space four or more rows in width and four or more inches long on one or more ears in the samples. This examination may be made at the time and on the ears tested for per cent of corn to cob. Examine the sides of the rows first, and if there is space the openings between the tip sides of the kernels can easily be detected. Turn the ear so that the end, either tip or butt, points toward you, and examine the ends of the rows down near the cob. When there is space, the openings between the tips of the kernels can easily be seen. This kind of space is extremely important from the fact that it is a result of poorly shaped kernels, usually low in vitality and lacking the important elements of composition.

\section{Per Cent of Corn}

The proportion of corn to cob is determined by using every other ear in the sample. Weigh the five ears. Shell off the grain. Weigh the cobs. Subtract the weight of cobs from the weight of ears, and the weight of the grain will be obtained. Divide the weight of the grain by the total weight of the five ears, and the per cent of corn will be obtained. For every per cent short of standard cut .5 point.

The proportion of $\mathrm{co}_{\perp} \Omega$ to $\mathrm{cob}$ depends in part on the maturity of the ears. If the ears are thoroughly dried out the percentage will be greater than in the moist ears.

Storing Seed Corn-Many corn breeders dry the seed ears by artificial heat. The ears are put up in a tight room arranged for ventilation as follows: Set $2 \times 8$ uprights along the floor the long way of the room, beginning with the first $\mathrm{nnw}$ about 18 inches from the 


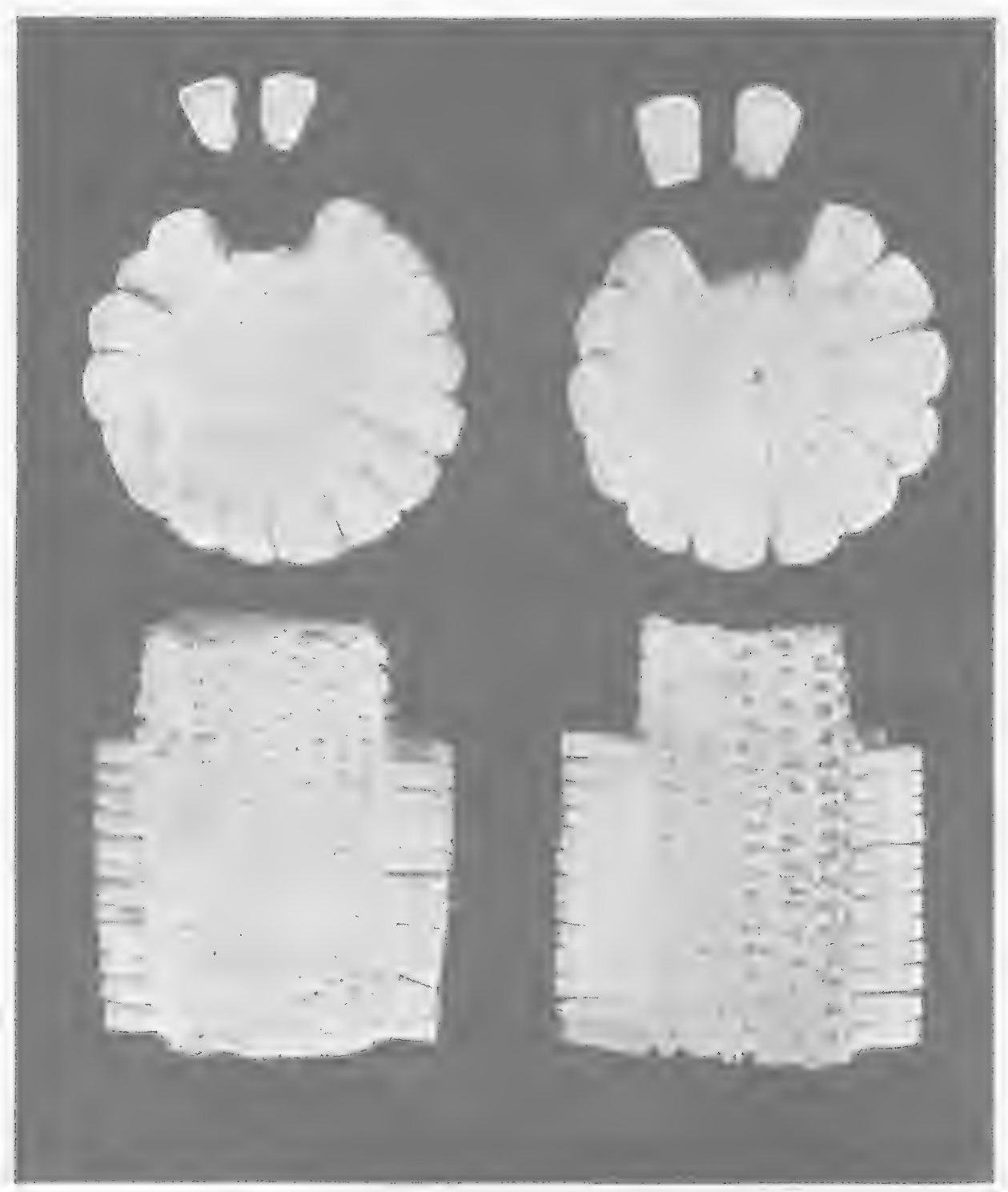

SIZE OF COB - TARGE COB AND SMTAT, TRRNETS CONTRASTED WITII SMLLLIER COB AND IAARGER TERNELS. FARS ABOUT THE SAME CIRCUMFERENCE (FROM YEARBOOK U. S. DEPT. AGRI. 1902) 
wall of the seed house. These uprights should be about ten feet apart. Now lay the first layer of corn between these uprights the length of the seed room, with the butts all lying together. Place a second layer on top of the first, with butts resting on the tips of the first. This arrangement will tend to keep an even layer. Repeat for six layers. Then nail 1x1-inch strips on the sides of the $2 \times 8$ 's, resting on one side on the tips and on the other side on the butts of the ears. Lay a second section of six rows of ears on top these pieces, and repeat until the cerling is reacherl. Set the next series of sections about two feet from the first, so that a man can walk between them. The third series of sections can be set within six inches of the second, so that every set of sections can be inspected on one side. When the corn is taken down it will be necessary to begin at the top and work downward. A heating stove can be set in the middle of the room. It should be surrounded by sheet iron, so that the corn around the stove will not be injured by heat so near by. In this way the ears will be dried out thoroughly in the fall, and the temperature can be controlled during the sudden changes in the wintex.

The value of these and other plans for thoroughly drying out the seed ears is illustrated by an experiment reported in the yearbook of the United States Department of Agriculture for 1902.*

*Improvement of Corn by Seed Selection, Yearbook U. S. Dept. Agr1 1902 pp 550-551. 


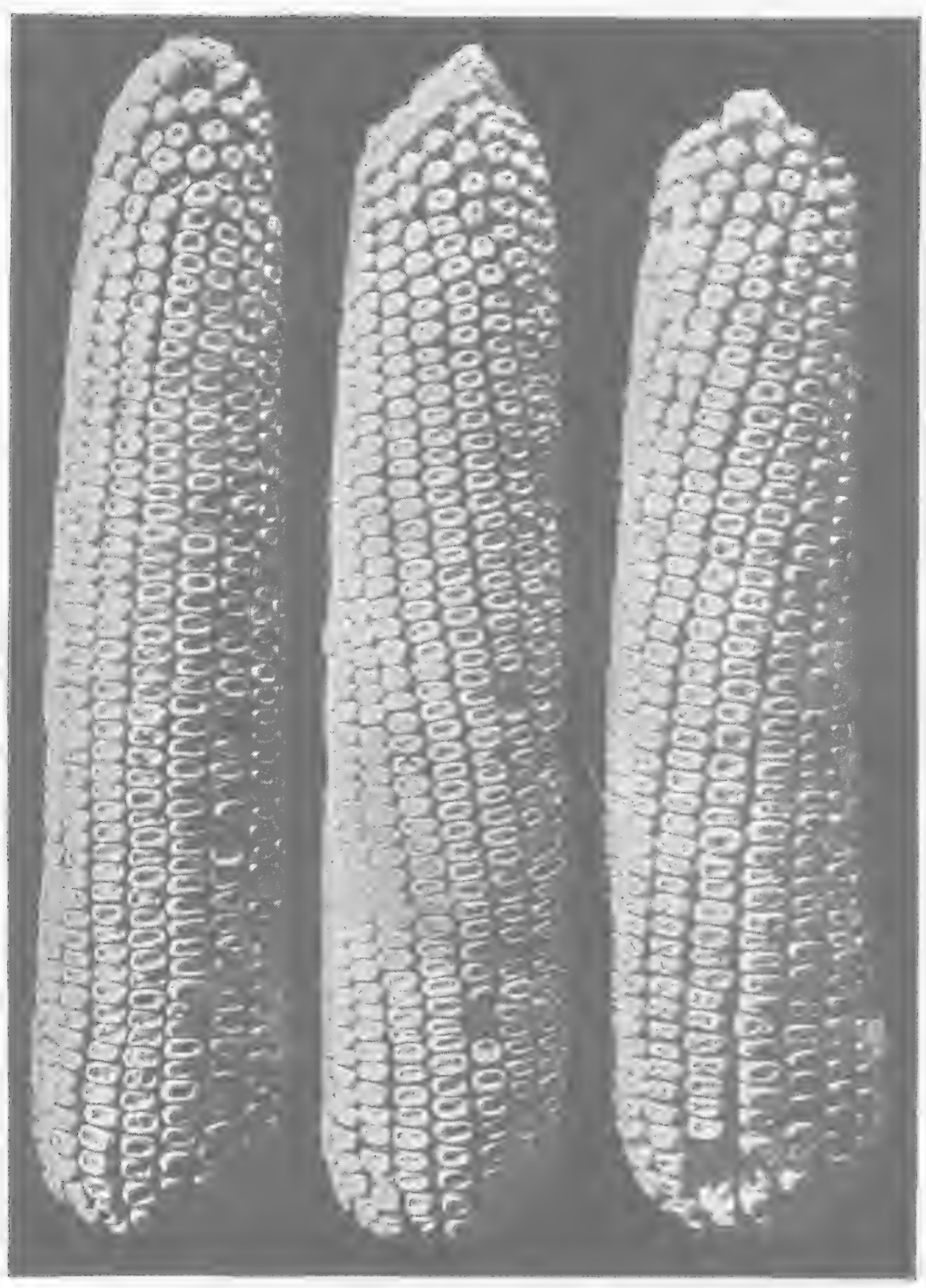

ARRANGEMENT UW ROWS-STRAIGHT, TURA TO LEWT, AND TLRY TO RIGH'T. YELLOW RACF 


\section{ARRANGement of Score Record}

The following pages give the most convenient arrangement for judging individual samples of corn and general exhibits. The first arrangement provides for first judging a sample, then by covering this score or not referring to it, rescoring it. Now by comparing these scores a close study may be made and a corrected and final score put down.

\section{FORM FOR INDIVIDUAL SAMPLE} IOWA SCORE CARD

Date

Number of Exhibit

Name of Variety

STANDARD OF VARIETY

Length

Circumference

Proportion Grain to $\mathrm{Cob}$

\begin{tabular}{|c|c|c|c|c|}
\hline POINTS & \begin{tabular}{|l|} 
PERFECT \\
SCORE \\
\end{tabular} & $\begin{array}{l}\text { FIRST } \\
\text { SCORKE }\end{array}$ & $\begin{array}{l}\text { SECOND } \\
\text { SCORE }\end{array}$ & $\begin{array}{l}\text { UURRECTED } \\
\text { SCORE }\end{array}$ \\
\hline $\begin{array}{l}\text { 1. Uniformity of exhibit } \\
\text { or trueness to type, or } \\
\text { breed characteristics.. }\end{array}$ & 10 & & & \\
\hline 2. Shape of ears........... & 10 & $\cdots$ & ........ & * \\
\hline 3. Color of ears $\left\{\begin{array}{l}\text { Grain... } \\
\text { Cob ... }\end{array}\right.$ & $\begin{array}{l}5 \\
5\end{array}$ & & & \\
\hline 4. Market condition ..... & 10 & & $\cdots \cdots \cdots \cdot$ & \\
\hline 5. Tips of ears............. & 5 & & & \\
\hline 6. Butts of ears........... & 5 & & & \\
\hline 7. Kernels $\left\{\begin{array}{l}\text { Uniformity.. } \\
\text { Shape ....... }\end{array}\right.$ & $\begin{array}{r}10 \\
5\end{array}$ & & & \\
\hline 8. Length of ears ......... & 10 & & & \\
\hline 9. Circumference of ears & 5 & & $\cdots$ & \\
\hline $10\left\{\begin{array}{l}\text { Space between rows. } \\
\text { "between furrows } \\
\text { and kernels at col }\end{array}\right.$ & $\begin{array}{l}5 \\
5\end{array}$ & & $\begin{array}{l}\cdots \\
\cdots\end{array}$ & \\
\hline $\begin{array}{l}\text { 11. Proportion of corn to } \\
\mathrm{cob} \ldots \ldots \ldots \ldots \ldots \ldots \ldots\end{array}$ & 10 & & … & \\
\hline$\eta$ & 100 & & & \\
\hline
\end{tabular}


MANUAL OF CORN JUDGING

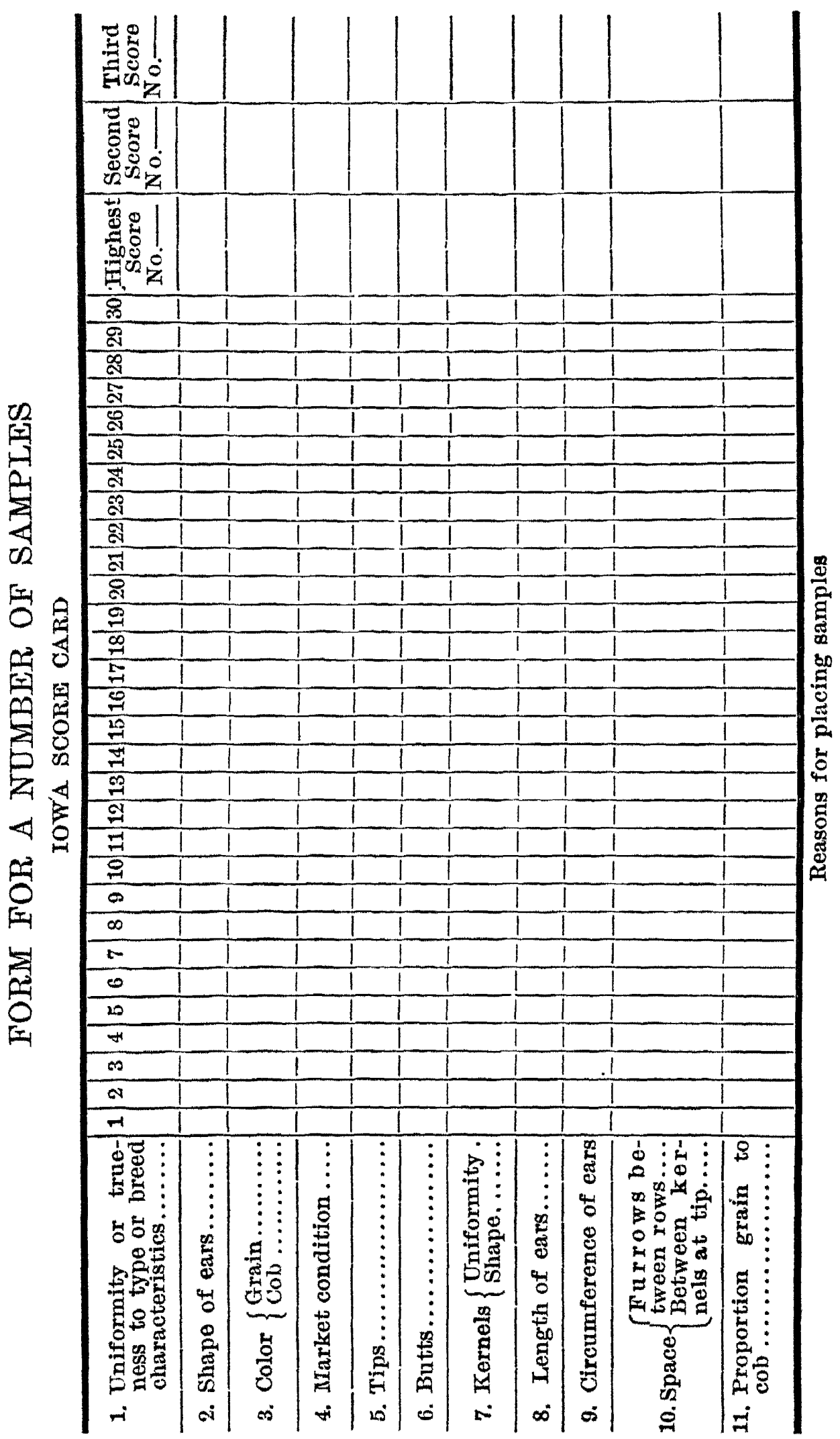




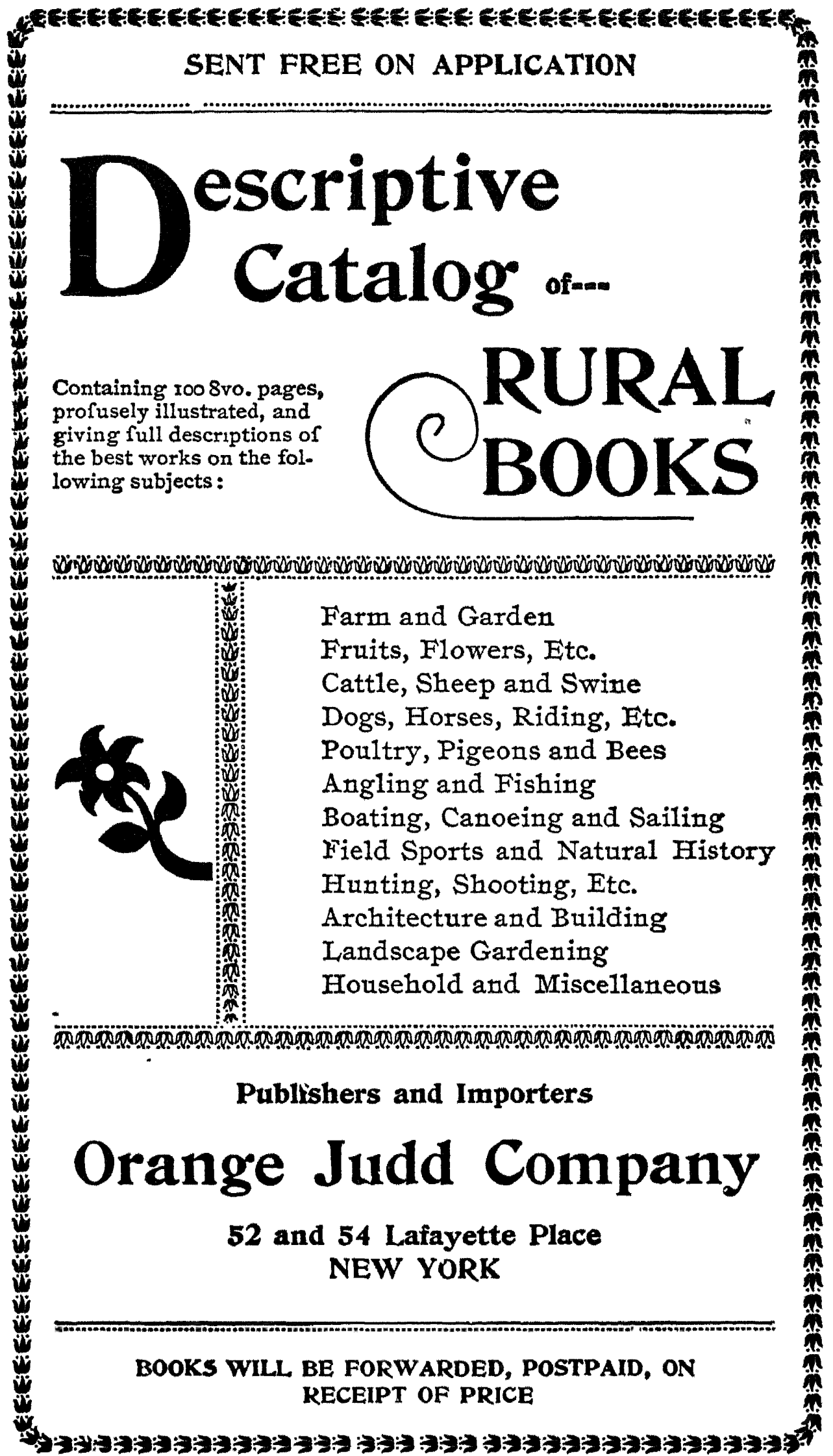




\section{STANDARD BOOKS.}

Forest Planting.

By H. Nicholas Jarchow, LL. D. A treatise on the care of woodlands and the restoration of the denuded timberlands on plains and mountains. The author has fully described those European methods which have proved to be most useful in maintaining the superb forests of the old world. This experience has been adapted to the different climates and trees of America, full instructions being given for forest planting of our various kinds of soil and subsoil, whether on mountain or valley. Illustrated. 250 pages. $5 \times 7$ inches. Cloth. $\$$ r.50

Soils and Crops of the Farm.

By George E. Morrow, M. A., and Thomas F. Hunt. The methods of making availabie the plant food in the soil are described in popular language. A short history of each of the farm crops is accompanied by a discussion of its culture. The useful discoveries of science are explained as applied in the most approved methods of culture. Illustrated. 3IO pages. $5 \times 7$ inches. Cloth. • • • • • $\$ 1.00$

\section{$I$ and Draining.}

A handbook for farmers on the principles and practice of diraining, by MANLY Mrzes, giving the results of his extencied experience in laying tile drains. The directions for the laying out and the construction of tile drains will enable the farmer to avoid the errors of imperfect construction, and the disappointment that must necessarily follow. This manual for practical farmers will also be found convenient for reference in regard to many questions that may arise in crop growing, aside from the special subjects of drainage of which it treats. Illustrated. 200 pages. 5x7 inches. Cloth. • • \$1.00

\section{Barn Plans and Outbuildings.}

Two hundred and fifty-seven illustrations. A most valuable work, full of ideas, hints, suggestions, plans, etc., for the construction of barns and outbuildings, by practical writers. Chapters are devoted to the economic erection and use of barns, grain barns, horse barns, cattle barns, sheep barns, cornhouses, smokehouses, icehouses, pig pens, granaries, etc. There are likewise chapters on birdhouses, doghouses, tool sheds, ventilators, roofs and roofing, doors and fastenings, workshops, poultry houses, manure sheds, barnyards, root pits, etc. 235 pages. $5 \times 7$ inches. Cloth. • • • \$1.00 


\section{STANDARD BOOKS.}

\section{Herbert's Hints to Horse Keepers.}

By the late Henry William Herberr (Frank Forester). This is one of the best and most popular works on the horse prepared in this country. A complete manual for horsemen, embracing: How to breed a horse; how to buy a horse; how to break a horse; how to use a horse; how to feed a horse; how to physic a horse (allopathy or homeopathy); how to groom a horse; how to drive a horse; how to ride a horse, etc. Beautifully illustrated. 425 pages. $5 \times 7$ inches. Cloth. . . . . . . . . . $\$ \mathrm{I} .50$ Diseases of Horses and Cattle.

By DR. D. MeIntosh, V. S., professor of veterinary science in the university of Illinois. Written expressly for the farmer, stockman and veterinary student. A new work on the treatment of animal diseases, according to the modern status of veterinary science, has become a necessity. Such an one is this volume of over 400 pages, written by one of the most eminent veterinarians of our country. Illustrated. 426 pages. 5x7 inches. Cloth. . . . . . \$1.75

\section{The Ice Crop.}

By Theron L. Hiles. How to harvest, ship and use ice. A complete, practical treatise for farmers, dairymen, ice dealers, produce shippers, meat packers, cold storers, and all interested in icehouses, cold storage, and the handling or use sof ice in any way. Including many recipes for iced dishes and beverages. The book is illustrated by cuts of the tools and machinery used in cutting and storing ice, and the different frrms of icehouses and cold storage buildings. Illustrated. 122 pages. $5 \times 7$ inches. Cloth. . . . . \$1.00

The Secrets of Health, or How Not to Be Sick, and How to Get Well from Sickness.

By S. H. Platr, A. M., M. D., late member of the Connecticut Eclectic Medical Society, the National Eclectic Medical Association, and honorary member of the National Bacteriological Society of America; our medical editor and author of "Talks With Our Doctor" and "Our Health Adviser." Nearly 600 pages. An index of 20 pages, so that any topic may be instantly consulted. A new departure in medical knowledge for the people-the latest progress, secrets and practices of all schools of healing made available for the common peoplehealth without medicine, nature without humbug, common sense without folly, science without fraud. 8I illustrations. 576 pages. $5 \times 7$ inches. Cloth. . . . . \$1.50 


\section{STANDARD BOOKS.}

\section{Hunter and Trapper.}

By Halsey T Hrasher, an old and experienced sportsman. The best modes of hunting and trapping are fully explained, and foxes, deer, bears, etc., fall into his traps readily by following his directions. Illustrated. 92 pages. $5 \times 7$ inches Cloth. $. \quad . \quad . \quad . \quad . \quad . \quad . \quad . \quad . \$ 0.50$

Batty's Practical Taxidermy and Home Decoration.

By JOSEPH $H$. BATTY, taxidermist for the government surveys and many colleges and nuseums in the United States. An entirely new and complete as. well as authentic work on taxidermy-giving in detail full directions for collecting and mounting animals, birds, reptiles, fish, insects, and general objects of natural history. I25 illustrations. 204 pages. 5x7 inches. Cloth. • • • • • \$1.00

\section{Hemp.}

By S. S. Boyce. A practical treatise on the culture of hemp for seed and fiber, with a sketch of the history and nature of the hemp plant. The various chapters are devoted to the soil and climate adapted to the culture of hemp for seed and for fiber, irrigating, harvesting, retting and machinery for handling hemp. Illustrated. II2 pages. 5x7 inches. Cloth.

Alfalfa.

By F. D. Coburn. Its growth, uses and feeding value. The fact that alfalfa thrives in almost any soil; that without reseeding, it goes on yielding two, three, four and sometimes five cuttings annually for five, ten, or perhaps roo years; and that either green or cured it is one of the most nutritious forage plants known, makes reliable information upon its production and uses of unusual interest. Such information is given in this volume for every part of America, by the highest authority. Illustrated. I64 pages. $5 \times 7$ inches. Cloth. \$0.50

\section{Talks on Manure.}

By JOSEPH HARRIS, M. S. A series of familiar and practical talks between the author and the deacon, the doctor, and other neighbors, on the whole subject of manures and fertilizers; including a chapter especially written for it by Sir John Bennet Lawes of Rothamsted, England. 366

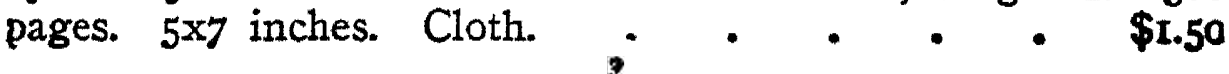




\section{SIANDARD BOOKS.}

\section{Practical Forestry.}

By ANDREw S. Fuller. A treatise on the propagation, planting and cultivation, with descriptions and the botanical and popular names of all the indigenous trees of the United States, and notes on a large number of the most valuable exotic species. Illustrated. 300 pages. $5 \times 7$ inches. Cloth. . . . . . . . . . \$1.50 Irrigation for the Farm, Garden and Orchard.

By Henry Stewart. This work is offered to those American farmers and other cultivators of the soil who, from painful experience, can readily appreciate the losses which result from the scarcity of water at critical periods. Fully illustrated. 276 pages. $5 \times 7$ inches. Cloth. . . \$I.OO

Irrigation Farming.

By Lute WrLcox. A handbook for the practical application of water in the production of crops. A complete treatise on water supply, canal construction, reservoirs and ponds, pipes for irrigation purposes, flumes and their structure, methods of applying water, irrigation of field crops, the garden, the orchard and vineyard, windmills and pumps, appliances and contrivances. New edition, revised, enlarged and rewritten. Prof usely illustrated. Over 500 pages. 5x7 inches. Cloth. . . . . . . . \$2.00 Ginseng, Its Cultivation. Harvesting, Marketing and Market Value.

By MAURICE G. KaINS, with a short account of its history and botany. It discusses in a practical way how to begin with either seed or roots, soil, climate and location, preparation, planting and maintenance of the beds, artificial propagation, manures, enemies, selection for market and for improvement, preparation for sale, and the profits that may be expected. This booklet is concisely written, well and profusely illustrated, and should be in the hands of all who expect to grow this drug to supply the export trade, and to add a new and profitable industry to their farms and gardens, without interfering with the regular work. New edition. Revised and enlarged. Illustrated. $5 \times 7$ inches. Cloth. . . - \$o.5०

\section{Truck Farming at the South.}

By A. Oemler. A work giving the experience of a suc-cessful grower of vegetables or "garden truck" for northerr markets. Essential to anyone who contemplates entering this profitable field of agriculture. Illustrated. 274 pages. 5X7 inches. Cloth. 


\section{STANDARD BOOKS.}

\section{Henderson's Practical Floriculture.}

By Peter Henderson. A guide to the successful propaga. tion and cultivation of florists' plants. The work is not one for florists and gardeners only, but the amateur's wants are constantly kept in mind, and we have a very complete treatise on the cultivation of flowers under glass, or in the open air. suited to those who grow flowers for pleasure as well as those who make them a matter of trade. New and enlarged edition. Beautifully illustrated. 325 pages. $5 \times 7$ inches. Cloth. \$1.50

Mushrooms. How to Grow Them.

By William Falconer. This is the most practical work on the subject ever written, and the only book on growing mushrooms published in America. The author describes how he grows mushrooms, and how they are grown for profit by the leading market gardeners, and for home use by the most successful private growers. Engravings drawn from nature expressly for this work. I70 pages. 5x7 inches. Cloth. \$1.00

Play and Profit in My Garden.

By E. P. ROE. The author takes us to his garden on the rocky hillsides in the vicinity of West Point, and shows us how out of it, after four years' experience, he evoked a profit of $\$$ rooo, and this while carrying on pastoral and literary labor. It is very rarely that so much literary taste and skill are mated to so much agricultural experience and good sense. Illustrated. 350 pages. $5 \times 7$ inches. Clnth. • • \$1.00

Fumigation Methods.

By Willis G. Johnson. A timely up-to-date book on the practical application of the new methods for destroying insects with hydrocyanic acid gas and carbon bisulphid, the most powerful insecticides ever discovered. It is an indispensable book for farmers, fruit growers, nurserymen, gardeners, florists, millers, grain dealers, transportation companies, college and experiment station workers, etc. Illustrated. 313 pages. 5x7 inches. Cloth. $\cdot . \cdot \cdot . \quad \$ 1.00$

Fungi and Fungicides.

By Prof. Clarence M. Weed. A practical manual concerning the fungous diseases of cultivated plants and the means of preventing their ravages. The author has endeavored to give such a concise account of the most important facts relating to these as will enable the cultivator to combat them intelligently. 90 illustrations. 222 pages. 5x7 inches.

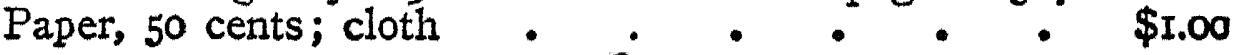




\section{STANDARD BOOKS.}

\section{Insects and Insecticides.}

By Clarence M. Weed, D. Sc., professor of entomology and zoology, New Hampshire college of agriculture. A practical manual concerning noxious insects, and methods of preventing their injuries. Many illustrations. 334 pages. 5x7 inches. Cloth. . . . . . . . \$1.50 How Crops Grow.

By Prof. Samuel W. Johnson of Yale college. New and revised edition. A treatise on the chemical composition, structure and life of the plant. This book is a guide to the knowledge of agricultural plants, their composition, their structure and modes of development and growth; of the complex organization of plants, and the use of the parts; the germination of seeds, and the food of plants obtained both from the air and the soil. The book is indispensable to all real students of agriculture. With numerous illustrations and tables of analysis. $4 \mathrm{1} 6$ pages. $5 \times 7$ inches. Cloth. \$1.50

Tobacco Leaf.

By J. B. Killebrew and Herbert Myrick. Its Culture and Cure, Marketing and Manufacture A practical handbook on the most approved rinethods in growing, harvesting, curing, packing and selling tobacco, with an account of the operations in every department of tobacco manufacture. The contents of this book are based on actual experiments in field, curing barn, packing house, factory and laboratory. It is the only work of the kind in existence, and is destined to be the standard practical and scientific authority on the whole subject of tobacco for many years. 506 pages and I50 original engravings. $5 \times 7$ inches. Cloth. . . . . . \$2.00

\section{Coburn's Swine Husbandry.}

By F. D. Cosurn. New, revised and enlarged edition. The breeding, rearing and management of swine, and the prevention and treatment of their diseases. It is the fullest and freshest compendium relating to swine breeding yet offered. Illustrated. 312 pages. 5x7 inches. Cloth. \$1.50 Home Pork Making.

The art of raising and curing pork on the farm. By A. W. Fulton. A complete guide for the farmer, the country butcher and the suburban dweller, in all that pertains to hog slaughtering, curing, preserving and storing pork productfrom scalding vat to kitchen table and dining room. Illustrated. I25 pages. $5 \times 7$ inches. Cloth. . . . \$0.50 


\section{STANDARD BOOKS.}

Harris on the Pig.

By Joseph HarRIS. New edition. Revised and enlarged by the author. The points of the various English and American brecds are thoroughly discussed, and the great advantage of using thoroughbred males clearly shown. The work is equally valuable to the farmer who keeps but few pigs, and to the breeder on an extensive scale. Illustrated. 3 I8 pages $5 \times 7$ inches. Cloth. . . . . . . . $\$ 1.00$ The Dairyman's Manual.

By Henry Stewart, author of "The Shepherd's Manual," "Irrigation," etc. A useft1 and practical work, by a writer who is well known as thoroughly familiar with the subject of which he writes. Illustrated. 475 pages. $5 \times 7$ inches Cloth. . . . . . . . . . . \$I.50

Feeds and Feeding.

By W. A. Henry. This handbook for students and stockmen constitutes a compendium of practical and useful knowledge on plant growth and anmal nutrition, feeding stuffs, feeding animals and every detall pertaining to this important subject. It is thorough, accurate and relable, and is the most valuable contribution to live stock literature in many years All the latest and best information is clearly and systematically presented, making the work indispensable to every owner of iive stock. 658 pages. $6 \times 9$ inches. Cloth. . . $\$ 2.00$ The Propagation of Plants.

By ANDREw S. Fuller. An eminently practical and useful work describing the process of hybridizing and crossing species and varieties and also the many different modes by which cultivated plants may be propagated and multiplied. Illustrated. 350 pages. $5 \times 7$ inches. Cloth. . . \$1.50 Gardening for Pleasure.

By Peter Henderson. A guide to the amateur in the fruit, vegetable and flower garden, with full descriptions for the greenhouse, conservatory and window garden. It meets the wants of all classes in country, city and village, who keep a garden for their own enjoyment rather than for the sale of products. Finely illustrated. 404 pages. $5 \times 7$ inches.

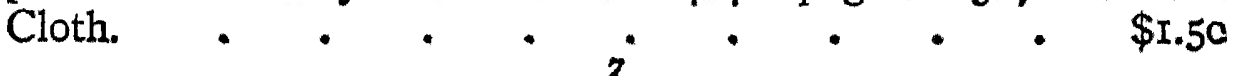


